\title{
Reestruturação, Requalificação e Dispensas: Um Estudo da Dinâmica do Mercado de Trabalho do Reino Unido, 1991-95*
}

Peter Elias

INTRODUÇÃO

॥R eestruturação" é um termo amplamente empregado para des-

R crever a multiplicidade de mudanças que ocorreram nas últimas duas décadas, abrangendo a redução do emprego em amplos segmentos das indústrias de transformação e de extração; a expansão do emprego em empresas de serviços, varejo e no ramo do "lazer"; a queda quantitativa de postos de trabalho operacionais e manuais pouco qualificados e o aumento das ocupações de nível superior, técnicas e gerenciais (Wilson e Linley, 2000). Além dessas mudanças de composição mais gerais, o termo "reestruturação" também é usado com referência a mudanças na organização do trabalho e da gerência, associadas à passagem das grandes organizações "verticalizadas" para as unidades menores, flexíveis e autônomas que dão mais destaque à gestão e cobrança de responsabilidade locais.

Embora os analistas possam discordar quanto à escala e extensão dessas mudanças, a maioria concorda que elas resultaram em grandes custos pessoais e sociais nas últimas duas décadas (Atkinson, 1993;

\footnotetext{
*[A tradução do original em inglês "Restructuring, Reskilling and Redundancy: A Study of the Dynamics of the UK Labour Market, 1991-95" é de Maria José Cyhlar Monteiro.]
}

DADOS - Revista de Ciências Sociais, Rio de Janeiro, Vol. 47, nº3, 2004, pp. 419 a 471. 
Hills, 1995; Jarvis e Jenkins, 1995). A escala do desemprego em massa do início da década de 1990 foi sem precedentes, superando os 3 milhões de pessoas, ou $12 \%$ da força de trabalho em 1993, enquanto o desemprego de longo prazo ${ }^{1}$ alcançou cerca de 1,5 milhão de trabalhadores em 1994 (Elias, 1996). Os dados também sugerem que a ampliação da distribuição dos rendimentos na década de 80 e início dos anos 90 poderia estar relacionada à "reestruturação" do mercado de trabalho, sem crescimento real no extremo inferior da distribuição de rendimentos associada à expansão dos empregos de baixa remuneração (Gosling, Machin e Meghir, 1994). O fato de aproximadamente um em cada cinco domicílios chefiados por pessoas em idade ativa não prever ninguém empregado em 1993-94 (ONS, 1997) deixa também claro que a desvantagem econômica não é apenas um fenômeno individual, mas tende a concentrar-se nos domicílios em função de características compartilhadas por seus membros (Gregg e Wadsworth, 1994; Elias, 1997).

Contudo, é difícil distinguir os efeitos da recessão daqueles dos processos de "reestruturação", alguns dos quais se manifestam por meio de movimentos de entrada e saída da recessão. Muito do que denominamos "reestruturação" pode ser exacerbado pela fase do ciclo econômico em que são feitas as observações. A crise de fins dos anos $80^{2}$, vinda depois da rápida expansão, impulsionada pelo consumo, de meados da década provavelmente distorceu os padrões de mobilidade e de alteração dos rendimentos. Este artigo examina o processo de reestruturação analisando os padrões de mobilidade da ocupação e dos ganhos dos participantes do mercado de trabalho em um período caracterizado por uma firme recuperação, 1991-95. Dá-se especial atenção ao grupo de pessoas dedicadas às atividades "manuais qualificadas (crafts)", um grupo de ocupações que declinou rapidamente no correr das décadas de 80 e 90 . O interesse nessas ocupações decorre do fato de que elas incorporam considerável treinamento vocacional - capital humano relacionado ao trabalho - que pode não ser transferido com facilidade a outras atividades.

O enfoque adotado embasa-se no exame secundário de dados nacionais encontrados em numerosas pesquisas de campo, principalmente a British Household Panel Study - BHPS, os censos demográficos de 1981 e 1991, e as Quarterly Labour Force Surveys. Essas fontes nos permitem explorar as seguintes questões: 
- Qual o papel desempenhado por movimentos voluntários, em oposição aos involuntários, no processo de reestruturação do mercado de trabalho? As pessoas que ficam sujeitas a movimentos "involuntários" sofrem prejuízos financeiros no longo prazo?

- É possível detectar trajetórias de "deslocamento" das ocupações manuais qualificadas? Sendo assim, como se caracterizam as oportunidades subseqüentes de emprego para os que seguem essas trajetórias?

- Em que medida o treinamento relacionado ao trabalho ameniza os impactos da reestruturação da força de trabalho? Há algum indício de que os trabalhadores deslocados que recebem treinamento profissionalizante estão mais capacitados a manter sua posição no mercado de trabalho do que os que não recebem esse treinamento?

O plano deste artigo é o seguinte. Na segunda seção, será examinado o conceito de "dispensa" (redundancy) como medida de perda de emprego involuntária, a partir de indicadores obtidos de diferentes fontes estatísticas para sentir a validade e a confiabilidade das informações sobre esse tipo de demissão. Na terceira, serão elaborados indicadores de mobilidade social a partir das respostas às cinco primeiras rodadas British Household Panel Survey. Essas medições serão validadas em confronto com outras fontes de dados. A quarta seção reúne informações sobre mudança ocupacional e mobilidade de rendimentos com informações sobre histórico de desemprego e dispensas, buscando elos entre essas ocorrências. A quinta parte examina a incidência e a extensão da capacitação profissional dos integrantes do painel estudado em um período de cinco anos, contrastando informações do Labour Force Survey com as da British Household Panel Survey, e tenta determinar se essa capacitação desempenha qualquer papel no sentido de amenizar o alto custo do deslocamento do trabalhador.

\section{CONCEITO E MEDIÇÃO DAS DISPENSAS}

\section{O Conceito de Dispensa (redundancy)}

A dispensa é definida, para propósitos estatísticos, como o término involuntário de um contrato de trabalho em decorrência de restrições econômicas ou jurídicas às atividades de uma organização. Esse tipo de demissão decorre, assim, da reação das organizações ou empresas às pressões do mercado (concorrência, recessão) ou de restrições jurí- 
dicas às suas atividades e é visto em geral como um ajustamento "em última instância" do mercado de trabalho ${ }^{3}$. As dispensas distinguem-se, assim, de outros tipos de desligamento (em que o contrato é rescindido involuntariamente, mas não por razões associadas em geral ao fechamento da empresa ou cortes de pessoal) e das rescisões decorrentes de fatores pessoais, como aposentadoria, doença, incapacidade e outros motivos voluntários. O interesse nas dispensas origina-se no fato de que elas refletem uma decisão do empregador mais do que do empregado. Essa "exogeneidade" é de grande utilidade para entender e diferenciar as conseqüências da mudança de emprego e o desemprego associado.

\section{Medição das Dispensas}

Antes da implantação da Labour Force Survey, as informações sobre dispensas resultavam de notificações exigidas por lei. Essas notificações só se aplicavam a estabelecimentos com dez ou mais empregados e nem todas eram notificadas. Depois, as informações passaram a basear-se nos dados coletados pela Labour Force Survey - LFS.

Para conhecer a trajetória subseqüente das pessoas afetadas por esse tipo de demissão, faz-se necessária uma fonte de dados longitudinal. Na British Household Panel Study, as informações pertinentes são coletadas por meio do histórico do ano que transcorre entre as rodadas de entrevistas sucessivas. Pergunta-se aos informantes pormenores de todos os empregos que tiveram nos doze meses anteriores ao mês de setembro que antecede a entrevista, incluindo diferentes cargos sob o mesmo empregador, e pede-se para selecionar dentro de uma lista a razão que melhor define o motivo que os levou a deixar de exercer aquela atividade ${ }^{4}$. Como ocorre com todos os dados retrospectivos, há uma possibilidade de que a resposta seja afetada por ocorrências subseqüentes. Por exemplo, uma pessoa que consegue um emprego melhor depois de ter sido dispensada pode declarar que a razão para deixar de fazer o que fazia anteriormente foi a de "ter encontrado um emprego melhor". Também é possível que pessoas demitidas por outras razões declarem ter sido afastadas em decorrência da extinção de seu cargo ou função porque é mais conveniente dizer que o ocorrido é conseqüência de fatores exógenos e não o resultado de não terem correspondido de alguma forma as expectativas de seu empregador. 
Para obter alguma indicação da validade dos dados sobre dispensas extraídos da British Household Panel Study foram feitas comparações com as informações da Labour Force Survey, a qual coleta as informações sobre esses tipos de demissão segundo uma ótica ligeiramente diferente. Desde o segundo trimestre de 1995, as perguntas feitas aos informantes são:

"Saiu de algum emprego remunerado nos últimos três meses? Se a resposta for afirmativa, pede-se para informar as razões de sua saída; o (a) senhor(a) foi dispensado ou aderiu a um plano de demissões voluntárias; sua saída teve outras razões (desligamento, fim de um contrato temporário, se demitiu por razões de saúde, de família ou outras, ou se aposentou, compulsória ou antecipadamente, ou por outros motivos)? Foi dispensado de qualquer outro emprego nos últimos três meses?"

Acumulando essas informações, a partir dos sucessivos levantamentos trimestrais, é possível computar taxas anualizadas ${ }^{5}$ de dispensas dos anos que vão de 1992 a 1995. O Quadro 1 compara essas taxas anuais com as informações obtidas a partir dos dados retrospectivos coletados nas diversas rodadas da BHPS.

\section{Quadro 1}

Comparação das Taxas de Dispensas com base na Labour Force Survey e na British Household Panel Study

\begin{tabular}{|l|cc|cc|}
\hline \multirow{2}{*}{ Período } & \multicolumn{2}{|c|}{$\begin{array}{c}\text { Dispensas estimadas } \\
\text { usando a QLFS }\end{array}$} & \multicolumn{2}{c|}{$\begin{array}{c}\text { Dispensas registradas } \\
\text { na BHPS }\end{array}$} \\
\cline { 2 - 5 } & Milhões & $\%^{1}$ & Número & $\%^{2}$ \\
\hline Dez. 91-nov. 92 & 1,251 & 4,9 & 297 & 5,0 \\
Dez. 92-nov. 93 & 1,052 & 4,2 & 263 & 4,6 \\
Dez. 93-nov. 94 & 0,817 & 3,2 & 227 & 3,9 \\
Dez. 94-nov. 95 & 0,773 & 3,0 & 190 & 3,4 \\
\hline
\end{tabular}

Fontes: LFS trimestral, primavera de 1993 a primavera de 1996 e rodadas 1 a 5 da BHPS. Notas: 1. Dispensas estimadas com base na QLFS expressas em \% do emprego total. 2. Dispensas declaradas na BHPS expressas como \% de todos os informantes que declararam ter trabalhado em algum momento do ano.

Pode-se ver a partir dessa comparação que as informações registradas na BHPS acompanham bem ${ }^{6}$, e não diferem significativamente ${ }^{7}$, 
das informações sobre dispensas geradas segundo a diferente ótica adotada na Quarterly Labour Force Survey - QLFS. Como os dados da LFS têm um período de referência trimestral, enquanto a BHPS adota como referência um ano (o histórico entre rodadas), esse resultado é satisfatório. Seria de se esperar que o período de referência mais longo da BHPS conduzisse a mais erros de memória e a um maior espaço para a reinterpretação posterior das razões para a saída de um dado emprego.

Visto que essas duas fontes parecem mostrar o fenômeno das dispensas de forma coerente nos dois tipos de pesquisa e no decorrer do tempo, pode-se considerar que a BHPS é um indicador da experiência geral da força de trabalho britânica a esse respeito. Essa é uma premissa importante para o restante do capítulo, facilitando a interpretação do comportamento subseqüente dos informantes que foram dispensados. Em particular, o que nos interessa é saber se essas pessoas experimentaram pelo menos uma fase de desemprego no mesmo ano em que foram dispensadas ${ }^{8}$.

O Quadro 2 mostra as informações sobre dispensas em cada ano anterior à rodada de entrevistas da BHPS, registrando o número de informantes demitidos por esse motivo que também declararam ter passado por pelo menos uma fase de desemprego após o desligamento. Com o avanço da retomada da economia, a proporção de informantes que declararam ter ficado desempregados por algum tempo diminui. Em média, quase metade dos empregados dispensados passa por uma fase de desemprego, o que poderia parecer bastante significativo, mas, dentro do contexto de todos os fluxos de desemprego que se registram a cada ano, as dispensas não constituem uma proporção substancial desses fluxos. A partir dos dados das QLFS, pode-se estimar que o número das dispensas caiu de cerca de 1,25 milhão em 1992 para cerca de 600 em 1995. Dadas as estimativas do Quadro 2, o número de pessoas que passaram por um período de desemprego pode ser calculado como variando entre cerca de $700 \mathrm{mil} \mathrm{em} 1992$ e $250 \mathrm{mil} \mathrm{em}$ 1995. As estimativas relativas ao número de pessoas que ficaram desempregadas ${ }^{9}$ variam em cerca de 3 milhões ao ano em 1992 e 2,75 milhões em 1995 (ONS, 1997). Assim, as dispensas representaram menos de um quarto de todos os novos requerimentos de benefício de- 
semprego em 1992, proporção que caiu para algo em torno de $10 \%$ dos novos requerimentos em 1995.

Quadro 2

Desempregados em Conseqüência das Dispensas

\begin{tabular}{|l|c|c|c|}
\hline \multirow{2}{*}{ Período } & $\begin{array}{c}\text { Número de informantes } \\
\text { que declararam rescisão } \\
\text { de contrato por dispensa }\end{array}$ & \multicolumn{2}{|c|}{$\begin{array}{c}\text { Dos quais, registraram pelo } \\
\text { menos uma fase de desemprego } \\
\text { subseqüente no mesmo período }\end{array}$} \\
\cline { 2 - 4 } & 314 & 187 & $\%$ \\
\hline Set. 1990-91 & 298 & 199 & 59 \\
Set. 1991-92 & 267 & 144 & 67 \\
Set. 1992-93 & 229 & 118 & 54 \\
Set. 1993-94 & 190 & 84 & 51 \\
Set. 1994-95 & & & 44 \\
\hline
\end{tabular}

Fonte: BHPS, rodadas 1 a 5 .

Outro trabalho sobre as características dos trabalhadores dispensados foi feito com base nas informações da QLFS (Potter, 1996). Nele se mostra, dentre outros fatores, que: (1) os trabalhadores de nível superior registram apenas metade da taxa de dispensas daqueles em ocupações manuais qualificadas e similares; (2) o setor de construção registra uma taxa de dispensas de quase duas vezes a encontrada na média de todos os setores; as taxas de dispensas no setor público foram de aproximadamente um quarto da média para todos os setores.

Essas correlações revelam algumas das variações que existem entre organizações e setores em reação a uma queda na demanda por mão-de-obra. Enquanto o setor público está mais protegido dos "choques" de demanda que podem provocar dispensas no setor privado, fica claro que a construção civil recorre a esse tipo de demissões como uma das principais formas de ajustamento do mercado de trabalho. Isso sugere que, na análise subseqüente dos fluxos de dispensas, será importante considerar tanto as influências ocupacionais quanto as setoriais.

\section{Indícios dos Efeitos das Dispensas e do Desemprego sobre os Rendimentos}

Apesar do interesse óbvio de se relacionar os fenômenos do mercado de trabalho, como as dispensas e o desemprego, a resultados observados, como mudanças nos rendimentos e na ocupação, até recente- 
mente pouco era feito nesse sentido no Reino Unido. Estudos geográficos (Green, 1994) indicam que há uma correlação entre indicadores de carência e áreas com altas perdas estruturais de empregos ${ }^{10}$. Blanchflower (1991) mostrou que os trabalhadores do Reino Unido que se consideram em "perigo de serem dispensados" recebiam cerca de $8 \%$ menos, cetiris paribus, do que aqueles que não sentiam esse risco. Jacobson et alii (1993), em um alentado estudo de trabalhadores com bastante tempo de serviço afastados (dispensados) de uma empresa dos EUA, mostrou que, entre aqueles trabalhadores às vésperas da demissão, a queda nos salários teve início três anos antes do seu afastamento e situava-se em torno de $15 \%$. Resultados semelhantes são encontrados em Ruhm (1991) e De la Rica (1995).

A perspectiva do afastamento parece, portanto, ter uma significativa influência negativa sobre os rendimentos. No caso dos trabalhadores dispensados, Jacobson et alii (1993) mostram que cinco anos após a rescisão a queda dos salários representava cerca de um quarto dos rendimentos anteriores ao afastamento ${ }^{11}$. Ruhm (1991) verificou uma perda de $10 \%$, quatro anos após o desligamento. Contudo, os dados europeus sobre os efeitos da dispensa e do desemprego sobre os rendimentos são bem menos nítidos. Ackum (1991) não encontrou qualquer relação entre desemprego e rendimentos subseqüentes no caso de jovens suecos, uma verificação que se repetiu entre trabalhadores mais velhos da Bélgica (Van Audenrode e Leonard, 1995). Gregory e Jukes (1997), que utilizaram um conjunto de dados sobre rendimentos e desemprego para homens na Grã-Bretanha, mostraram que a duração de uma fase de desemprego tem efeitos de longo prazo sobre os rendimentos sobretudo para os mais velhos e para os que ganham mais do que a média.

Essas observações aparentemente contraditórias sobre os efeitos das dispensas e do desemprego sobre os rendimentos podem ser o resultado de uma falha na distinção entre perda de emprego voluntária e involuntária. Parece razoável supor que os empregados que transitam voluntariamente entre empregadores sem passar por fases de desemprego têm menor probabilidade de sofrer uma queda nos rendimentos do que aqueles que são dispensados e ficam desempregados. Essas distinções entre dispensas como causa de mudança de emprego versus outras razões e entre mudanças de emprego que compreendem uma fase de desemprego e os que não a incluem parecem meios adequados de explorar o impacto da mudança de emprego sobre os ren- 
dimentos e a mobilidade ocupacional. Isso será feito nas seções seguintes. Primeiro, analisaremos e caracterizaremos a mobilidade ocupacional em termos de qualificações, o movimento de trabalhadores entre empregos que trazem implicações significativas em relação a experiência exigida e competência ocupacional para levar adiante as tarefas associadas ao emprego. Segundo, as variações nos rendimentos serão examinadas na forma de movimentos entre decis em torno da distribuição dos ganhos. Finalmente, analisaremos com algum pormenor a relação entre a mobilidade ocupacional, a variação dos rendimentos e as dispensas e o desemprego.

\section{QUALIFICAÇÕES E MUDANÇA OCUPACIONAL}

\section{Definição de Grupos de Qualificação}

O estudo da mudança ocupacional é facilitado pela classificação dos dados de emprego segundo ocupação, registrando o movimento das pessoas empregadas entre as categorias da classificação. A esse respeito é importante observar que a mudança ocupacional é diferente de uma mudança de cargo ou de empregador. Os "cargos" podem ser descritos como pacotes de tarefas, geralmente definidas pelo empregador e projetadas para serem desempenhadas por uma pessoa. $\mathrm{Mu}$ danças no cargo podem surgir sem troca de empregador e não dão, necessariamente, lugar a uma mudança na "ocupação" - termo classificatório que define um conjunto de cargos que dividem algumas características comuns em termos da base conceitual de classificação subjacente. Assim, o estudo da mudança ocupacional exige o uso de uma classificação cuja base conceitual seja adequada à natureza do estudo.

O presente trabalho concentra-se particularmente nos processos de "requalificação" e "desqualificação", com o que se quer fazer referência à formação ou subutilização da competência ocupacional - a relação entre a capacidade de uma pessoa para desempenhar efetiva e eficientemente as tarefas associadas a um cargo específico e as exigências para essa competência dentro do trabalho. Embora a "qualificação" possa ser interpretada de várias maneiras que vão da destreza manual, passando pela utilização de um corpo de conhecimento especializado, a um indicador de status social, neste estudo o termo será usado como medida do período normalmente necessário para que uma pessoa se torne competente na execução de dado trabalho. Dada 
que esta é a base conceitual para a Classificação Ocupacional Padrão de 1990 - SOC $90^{12}$, a qualificação é operacionalizada por meio da referência a grupos unitários [famílias] de ocupação da SOC90.

O Quadro 3 mostra a relação entre os níveis de qualificação teóricos usados na elaboração da SOC90 e seus grupos, principal, subprincipal e secundário. Nela foram identificados quatro "níveis" de competência. No quarto nível, estão os cargos para os quais a competência ocupacional exige um diploma universitário ou equivalente, e/ou um período associado de experiência no trabalho, abrangendo as categorias gerenciais mais altas e as atividades exercidas por pessoal de nível superior. O terceiro, denominado "intermediário", reúne os postos gerenciais médio e inferior, gerentes de pequenas empresas, atividades profissionais e técnicas, representantes de vendas e ocupações manuais qualificadas. Para os propósitos deste estudo, as ocupações no nível da SOC90 foram subdivididas em dois grupos: ocupações intermediárias manuais não qualificadas e ocupações manuais qualificadas. Todas as outras ocupações, abrangendo os dois níveis inferiores de qualificação da SOC90 foram agrupadas em uma única categoria denominada "outras ocupações"13.

\section{Mudanças na Estrutura Ocupacional}

Dado que a Classificação de Ocupações só foi adotada por todas as fontes nacionais de dados ocupacionais no início da década de 90, é difícil desenvolver informações relativas às tendências de longo prazo na estrutura de qualificações da população empregada. Contudo, uma amostra recodificada (1/2\%) do Censo Demográfico de 1981 para a Inglaterra e País de Gales proporcionou informações suficientes para a montagem de dados para aquele ano. O Quadro 4 mostra as estimativas resultantes da estrutura de qualificações da população empregada elaboradas a partir dos Censos Demográficos, para os anos de 1981 e 1991, da LFS, em 1991 e 1995 e da BHPS para 1991 e 1995. Como se vê, apesar das diferenças no tamanho das amostras, nas metodologias e nas técnicas de codificação, o quadro que surge dessas comparações mostra um alto grau de coerência. Onde as datas se sobrepõem (Censo 1991 e LFS 1991, BHPS 1991 e LFS 1991, BHPS 1995 e LFS 1995), as estimativas correspondentes da estrutura de qualificações da população empregada estão impressionantemente pró$\operatorname{ximas}^{14}$. 


\section{Quadro 3}

\section{Grupos e Níveis de Qualificação e Estrutura da Classificação \\ de Ocupações de 1990}

\begin{tabular}{|c|c|c|c|}
\hline $\begin{array}{l}\text { Grupo de } \\
\text { qualificação }\end{array}$ & $\begin{array}{c}\text { Nível de } \\
\text { qualificação }\end{array}$ & $\begin{array}{c}\text { Grupos principal e } \\
\text { subprincipal da SOC } 90\end{array}$ & $\begin{array}{l}\text { Grupos secundários } \\
\text { que as constituem }\end{array}$ \\
\hline \multirow[t]{2}{*}{$\begin{array}{l}\text { Altamente } \\
\text { qualificado }\end{array}$} & 4 & $\begin{array}{l}\text { Administradores e gesto- } \\
\text { res (exceto gerentes de es- } \\
\text { critório e administrado- } \\
\text { res/proprietários na agri- } \\
\text { cultura e nos serviços) }\end{array}$ & $10,11,12,15,19$ \\
\hline & 4 & $\begin{array}{l}\text { Ocupações de nível supe- } \\
\text { rior }\end{array}$ & $\begin{array}{l}20,21,22,23,24,25,26, \\
27,29\end{array}$ \\
\hline \multirow[t]{3}{*}{$\begin{array}{l}\text { Intermediá- } \\
\text { rio (manual } \\
\text { não qualifi- } \\
\text { cado) }\end{array}$} & \multirow[t]{3}{*}{3} & $\begin{array}{l}\text { Gerentes de escritório e } \\
\text { administradores/pro- } \\
\text { prietários na agricultura } \\
\text { e nos serviços }\end{array}$ & $13,14,16,17$ \\
\hline & & $\begin{array}{l}\text { Ocupações de nível supe- } \\
\text { rior e técnico relaciona- } \\
\text { das }\end{array}$ & $\begin{array}{l}30,31,32,33,34,35,36 \\
37,38,39\end{array}$ \\
\hline & & $\begin{array}{l}\text { Compradores/corretores } \\
\text { e representantes de ven- } \\
\text { das }\end{array}$ & 70,71 \\
\hline $\begin{array}{l}\text { Intermediá- } \\
\text { rio (manual } \\
\text { qualificado) }\end{array}$ & 3 & $\begin{array}{l}\text { Ocupações manuais qua- } \\
\text { lificadas e afins }\end{array}$ & $\begin{array}{l}50,51,52,53,54,55,56, \\
57,58,59\end{array}$ \\
\hline \multirow[t]{6}{*}{$\begin{array}{l}\text { Outras } \\
\text { ocupações }\end{array}$} & \multirow[t]{6}{*}{2,1} & $\begin{array}{l}\text { Ocupações burocráticas e } \\
\text { secretariais }\end{array}$ & $40,41,42,43,44,46,49$ \\
\hline & & $\begin{array}{l}\text { Ocupações em serviços } \\
\text { pessoais e de proteção }\end{array}$ & $\begin{array}{l}60,61,62,63,64,65,66, \\
67,69\end{array}$ \\
\hline & & $\begin{array}{l}\text { Pessoal de vendas (exce- } \\
\text { to compradores/correto- } \\
\text { res, representantes de } \\
\text { vendas) }\end{array}$ & $72,73,79$ \\
\hline & & $\begin{array}{l}\text { Trabalhadores na produ- } \\
\text { ção industrial e operado- } \\
\text { res de máquinas }\end{array}$ & $\begin{array}{l}80,81,82,83,84,85,86, \\
87,88,89\end{array}$ \\
\hline & & $\begin{array}{l}\text { Outras ocupações na } \\
\text { agricultura, silvicultura e } \\
\text { pesca }\end{array}$ & 90 \\
\hline & & $\begin{array}{l}\text { Outras ocupações não } \\
\text { qualificadas }\end{array}$ & $91,92,93,94,95,96$ \\
\hline
\end{tabular}

Fonte: Elias (1995). 


\section{Quadro 4}

Alterações na Estrutura de Qualificações do Emprego ${ }^{1}$ na Grã-Bretanha, 1981-95: Comparação entre Três Fontes de Dados

\begin{tabular}{|l|cc|cc|cc|}
\hline & \multicolumn{2}{|c|}{ Censo $^{2}$} & \multicolumn{2}{c|}{ LFS $^{3}$} & \multicolumn{2}{c|}{ BHPS $^{\mathbf{4}}$} \\
\hline Grupo de qualificação/gênero & $\mathbf{1 9 8 1}$ & $\mathbf{1 9 9 1}$ & $\mathbf{1 9 9 1}$ & $\mathbf{1 9 9 5}$ & $\mathbf{1 9 9 1}$ & $\mathbf{1 9 9 5}$ \\
\hline Homens & & & & & & \\
Altamente qualificado & 14,5 & 18,0 & 19,0 & 21,9 & 18,0 & 21,1 \\
Intermediário (não qualificado) & 17,3 & 19,8 & 19,8 & 19,7 & 19,8 & 21,2 \\
Intermediário (manual qualificado) & 25,8 & 24,0 & 24,3 & 20,8 & 24,1 & 20,7 \\
Outras ocupações & 42,3 & 38,1 & 37,0 & 37,6 & 38,2 & 37,1 \\
\hline Total & $\mathbf{1 0 0 , 0}$ & $\mathbf{1 0 0 , 0}$ & $\mathbf{1 0 0 , 0}$ & $\mathbf{1 0 0 , 0}$ & $\mathbf{1 0 0 , 0}$ & $\mathbf{1 0 0 , 0}$ \\
\hline Mulheres & & & & & & \\
Altamente qualificado & 8,3 & 11,6 & 12,0 & 14,6 & 11,0 & 13,6 \\
Intermediário (não qualificado) & 13,9 & 18,1 & 17,5 & 17,4 & 18,4 & 18,0 \\
Intermediário (manual qualificado) & 4,9 & 3,8 & 3,8 & 2,9 & 3,2 & 2,7 \\
Outras ocupações & 72,9 & 66,5 & 66,7 & 65,1 & 67,5 & 65,7 \\
\hline Total & $\mathbf{1 0 0 , 0}$ & $\mathbf{1 0 0 , 0}$ & $\mathbf{1 0 0 , 0}$ & $\mathbf{1 0 0 , 0}$ & $\mathbf{1 0 0 , 0}$ & $\mathbf{1 0 0 , 0}$ \\
\hline
\end{tabular}

Notas: 1. "Emprego" inclui trabalhadores assalariados e por conta própria.

2. Os dados censitários só se referem a Inglaterra e País de Gales.

3. Os dados da Labour Force Survey (LFS) referem-se apenas ao segundo trimestre de cada ano.

4. Os dados da British Household Panel Study (BHPS) registram as ocupações dos integrantes do painel amostral em outubro/novembro/dezembro de cada ano. O painel admite novos integrantes quando estes atingem 16 anos e perde integrantes em função do desgaste da amostra.

Como já mencionado, o termo "reestruturação" é usado para denominar várias mudanças que se registram no mercado de trabalho. No presente contexto, o termo é utilizado para abranger os principais movimentos do emprego e as consequentes mudanças ocupacionais. No Quadro 4, podemos observar que há impactos diferentes no emprego de homens e de mulheres. O contínuo aumento da participação feminina na força de trabalho, de $68 \%$ das mulheres em idade ativa em 1986 para $71 \%$ em 1997 (Sly et alii, 1997), foi determinado pelo aumento do trabalho em tempo parcial em ramos como o varejista e pelo relativo aumento dos avanços que as mulheres têm conseguido em anos recentes em termos de seu acesso a empregos altamente qualificados (ocupações gerenciais de alto nível e ocupações que exigem nível superior). Isso pode ser visto se comparando as mudanças na composição do emprego feminino, na categoria das "altamente qualificadas", registradas entre 1981 e 1995 (de quase 3,5 pontos percentuais em uma década), como a correspondente mudança nos quatro 
anos seguintes (crescimento de mais de 2,5 pontos percentuais). Contudo, as mulheres ainda têm uma participação muito menor em todos os empregos altamente qualificados, como se pode ver na Figura 1, que contrasta a estrutura de qualificações do emprego de homens e de mulheres verificada entre 1991 e 1995, tal como mostrado tanto pela BHPS quanto pela LFS. Em 1995, o número de mulheres em empregos altamente qualificados era proporcionalmente de apenas metade dos ocupados pelos homens.

No caso dos homens, as duas mudanças mais significativas, evidentes na observação do Quadro 4 e na Figura 1, são o contínuo crescimento dos empregos altamente qualificados e o declínio na categoria dos empregos de manuais qualificados. É interessante notar que esta última categoria passou a cair mais rapidamente nos anos que se seguiram à recessão, 1991-95, do que no período anterior. De 1981 a 1991, a categoria de qualificação intermediária "manual qualificada" caiu 1,8 pontos percentuais, correspondendo a uma redução líquida de quase um quarto de milhão de empregos desse grupo. No quadriênio subseqüente, tanto a LFS quanto a BHPS mostram que o grupo ocupacional caiu 3,5 pontos percentuais - uma redução líquida de mais meio milhão de empregos na Grã-Bretanha.

\section{Mobilidade Ocupacional}

Dada a aceleração observada na queda das ocupações técnicas masculinas durante a recuperação da recessão em 1991-95, e o continuado crescimento do emprego feminino na categoria das ocupações altamente qualificadas apesar da expansão do emprego parcial de mulheres em atividades pouco qualificadas, é interessante identificar as variações anuais na estrutura ocupacional usando informações de cada uma das sucessivas rodadas da BHPS. A Figura 2 revela essas mudanças, apresentando os números da amostra em cada uma das quatro categorias de qualificação e os movimentos entre categorias como percentuais desses números.

Examinando primeiro os fluxos de entrada e saída do emprego em base anual (representados pelas setas verticais na Figura 2), podemos ver que os fluxos de saída de "outras ocupações" (a categoria de baixa qualificação) são geralmente maiores do que os da maioria das demais categorias de qualificação com exceção da categoria manual qualificada, que apresenta fluxos de saída do emprego que são ape- 
Peter Elias

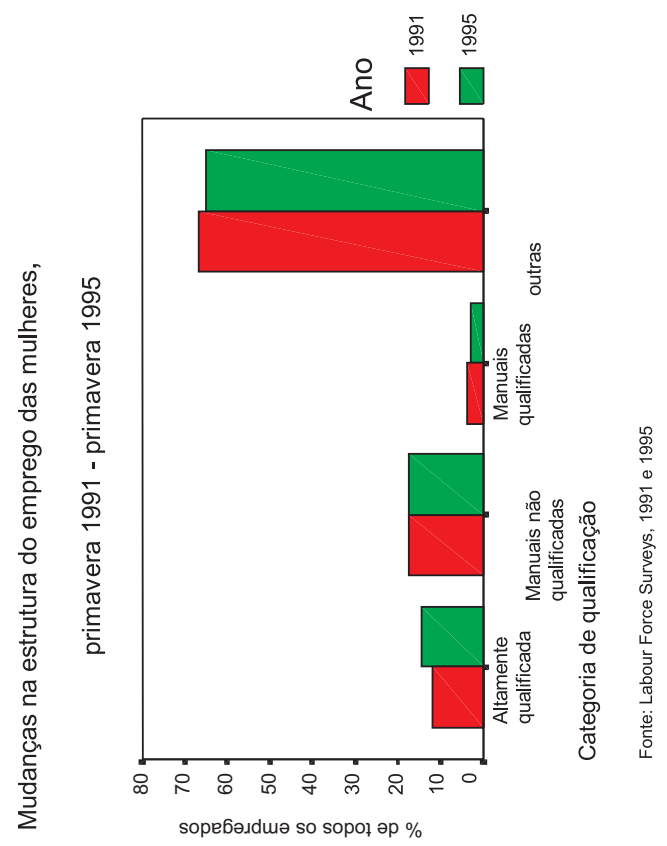

목

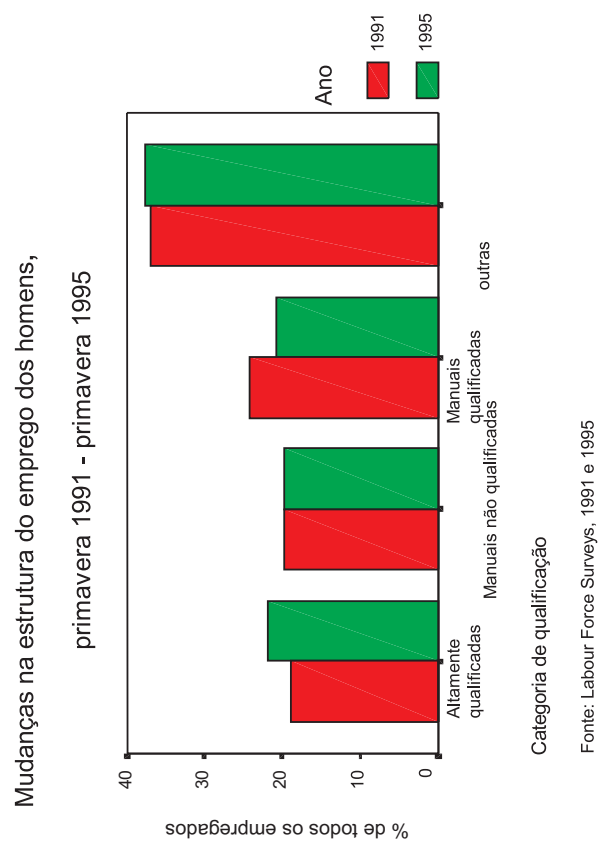


Reestruturação, Requalificação e Dispensas: Um Estudo da Dinâmica...

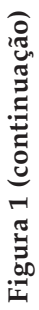
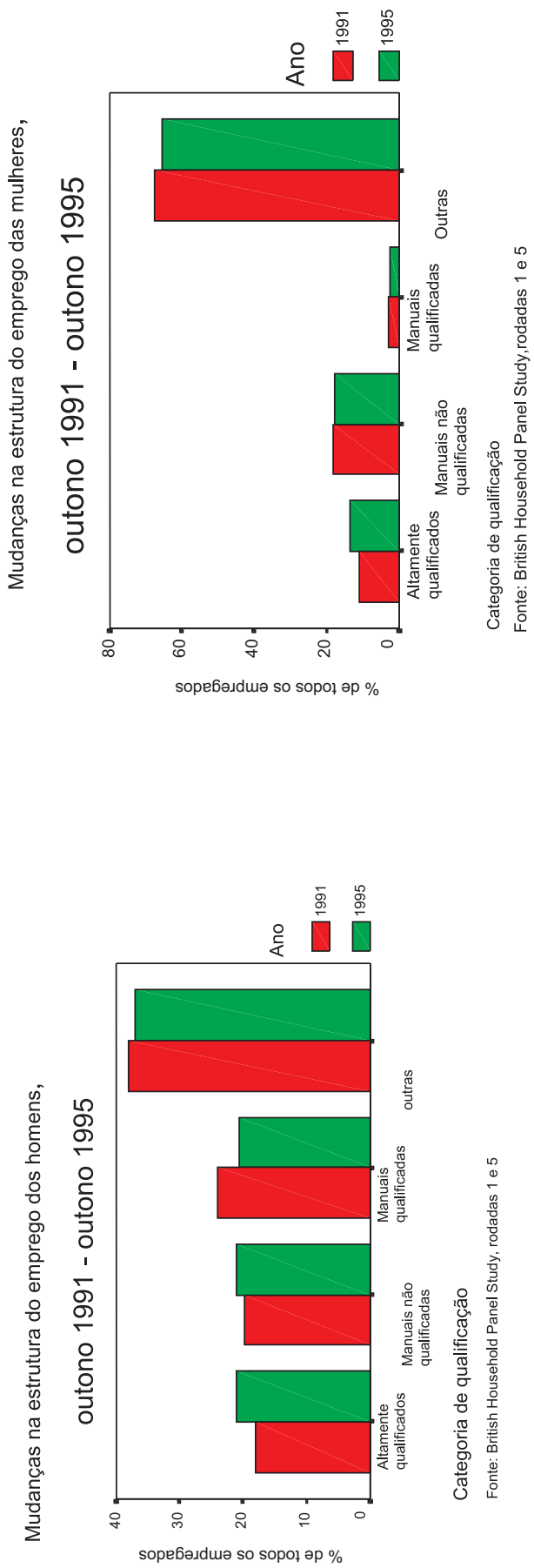

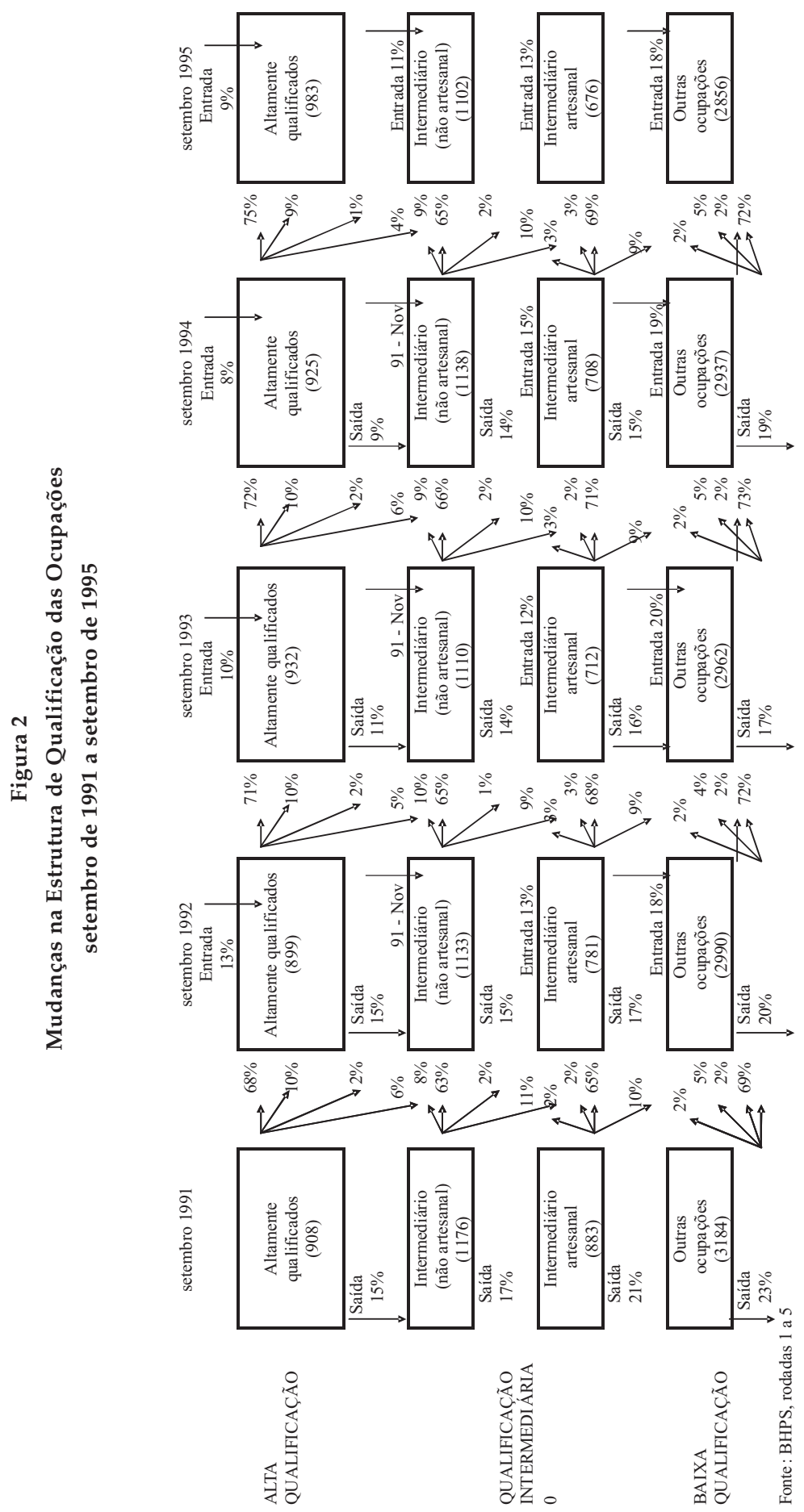
nas ligeiramente menores. Em todas as categorias, a escala dos fluxos de entrada dos desempregados é essencialmente semelhante a das saídas para o desemprego.

O efeito líquido desses movimentos interocupacionais, junto com as variações dos fluxos de entrada e saída do emprego, conforme registrados à época de cada entrevista, podem ser vistos examinando-se o tamanho da amostra em cada categoria (que aparece entre parêntesis em cada caixa). O declínio na categoria de ocupações manuais qualificadas é evidente: o número de informantes empregados nesse segmento cai de 883 pessoas em 1991 para 676 pessoas em 1995. Essa redução ocorre tanto pelas variações dos fluxos entre grupos ocupacionais quanto pela diferença nos fluxos de entrada e saída do não emprego. A maior parte dessas diferenças surgiu entre 1991 e 1992, quando a saída para o não-emprego foi de $21 \%$ da categoria e a volta de não-empregados foi de apenas 13\% em 1992. Embora esta volta tivesse se mantido bastante constante nos anos posteriores, a magnitude do não emprego nos anos subseqüentes caiu substancialmente. Além disso, a saída da categoria das ocupações manuais qualificadas para outras ocupações foi bem maior em 1991-92 do que em períodos posteriores. Esses dois efeitos, as saídas líquidas para o não-emprego e para a categoria de "outras ocupações" podem ser descritas como um impacto recessivo, mas esse rótulo não explicaria por que a categoria continuou declinando. Em todos os anos seguintes ao período 1991-92, a entrada de pessoas não empregadas na categoria manual qualificada é menor do que a saída para o não-emprego, indicando que influências estruturais de longo prazo estão em ação e que estas podem estar associadas a um processo de renovação ${ }^{15}$ do mercado de trabalho.

O crescimento da categoria "altamente qualificado", embora não tão significativo quando houve a redução no grupo "manual qualificado", parece ter sido efeito de um processo diferente. A maior parte desse crescimento ocorreu entre 1994 e 1995. Embora a entrada nessa categoria de pessoas vindas do segmento intermediário manual não qualificado tenha permanecido bastante constante, a saída do grupo "altamente qualificado" para o grupo intermediário e para outras ocupações caiu gradativamente no quadriênio. Entre 1994 e 1995 a entrada de pessoas vindas do não-emprego quase igualou a saída de pessoas para o não-emprego, mas os fluxos para as outras três catego- 
rias ocupacionais totalizaram 130 pessoas, enquanto a entrada de pessoas vindas dessas categorias somou 190.

Em resumo, o período de 1991 a 1995 registrou uma aceleração nas mudanças da estrutura de qualificações da população quando comparado ao de 81 a 91. Embora as comparações entre esses períodos sejam exacerbadas pelo fato de que o biênio 1990-91 marcou o auge da recessão que se seguiu ao chamado "boom de Lawson", pode-se dizer que a redução das ocupações manuais qualificadas reflete tendências estruturais de prazo mais longo, como ocorre com o continuado crescimento dos empregos altamente qualificados - ocupações de nível superior e de alta gerência. As mudanças na magnitude dessas categorias ocupacionais decorrem da entrada e saída de pessoas da situação de não-emprego para a de emprego e de movimentos entre categorias. Os movimentos interocupacionais envolvem o trânsito de pessoas (principalmente homens) da categoria manual qualificada para as "outras" ocupações e da "ascensão" de pessoas das ocupações manuais não qualificadas para o grupo dos altamente qualificados.

\section{Mudança Ocupacional, Dispensas e Desemprego}

As pressões originárias das forças da globalização e da mudança tecnológica traduzem-se, por intermédio do mercado de bens e serviços, em novas demandas de mão-de-obra. Estas, por sua vez, criam, por meio do crescimento e da extinção das organizações, novos cargos ou eliminam os já existentes. Alguns participantes do mercado de trabalho transitam sem dificuldades entre cargos, seja como parte de uma "progressão de carreira", ou seja, uma bem definida trajetória ocupacional; outros são dispensados e/ou ficam desempregados no curso de sua vida de trabalho. Esses episódios - dispensas e desemprego - representam atritos no processo de reestruturação. Os programas de apoio ao trabalhador, envolvendo serviços de orientação, possíveis indenizações por dispensa e esquemas de reconversão de mão-deobra, destinam-se a minorar as potenciais conseqüências negativas para as pessoas atingidas por esses atritos. Contudo, com exceção dos poucos estudos mencionados na seção "Indícios dos Efeitos das Dispensas e do Desemprego sobre os Rendimentos", ainda desconhecemos os efeitos de longo prazo dessas mudanças estruturais e temos pouco conhecimento a respeito da eficácia dos "remédios" formulados para promover a inserção ou a reinserção no mercado de trabalho daqueles atingidos pelo desemprego e pelas dispensas. 
Para dar alguma noção da escala desses atritos e de sua localização dentro da estrutura do mercado de trabalho, o Quadro 5 mostra o percentual de pessoas, em cada uma das quatro categorias ocupacionais definidas para os propósitos deste estudo, que passaram por alguma fase de desemprego e/ou dispensa durante os anos de 1990-91 e 1994-95. Examinando primeiramente o caso do desemprego, observa-se um nítido gradiente em cada um dos períodos anuais nas quatro categorias ocupacionais. A incidência de desemprego na de qualificação mais baixa é mais do que o dobro da registrada no grupo altamente qualificado. As ocupações manuais qualificadas sempre mostram uma maior incidência de fases de desemprego do que as ocupações manuais não qualificadas. Durante os cinco anos examinados, o desemprego aumentou e depois teve uma queda, indicando o "desenrolar" da recessão de 1990-91 e a gradual recuperação no período posterior. Essa tendência não é de forma alguma uniforme, mostrando que a recuperação econômica teve um efeito desigual sobre a demanda por qualificações.

Já o caso das dispensas é mais uniforme entre as quatro categorias de qualificação e o decorrer do tempo. Em geral, as taxas de dispensas são aproximadamente metade da taxa de incidência de desemprego. Embora já se tenha mostrado que, em termos nacionais, as dispensas atingiram o auge no período 1990-91, sua taxa no grupo de ocupações manuais não qualificadas continuou aumentando em 1992-93, enquanto caía no caso das manuais qualificadas em 1992-93, subindo novamente em 1993-94, antes de cair rapidamente para o ponto mais baixo dos cinco anos em 1994-95.

Em resumo, esse "instantâneo" de cinco anos de desemprego e dispensas mostra que a reestruturação econômica é um processo irregular em termos dos atritos no mercado de trabalho que traz em sua esteira. Embora a experiência do desemprego pareça seguir uma trajetória razoavelmente previsível em termos de sua localização dentro do espectro ocupacional e em relação ao crescimento econômico, o caso das dispensas é menos previsível, apesar de sua distribuição mais uniforme entre categorias de qualificação.

Embora o Quadro 5 indique a localização do desemprego e das dispensas segundo categorias de qualificação e no decorrer do tempo, ele não esclarece o elo existente entre essas ocorrências. Mais adiante exploraremos com mais pormenores os efeitos combinados das dis- 


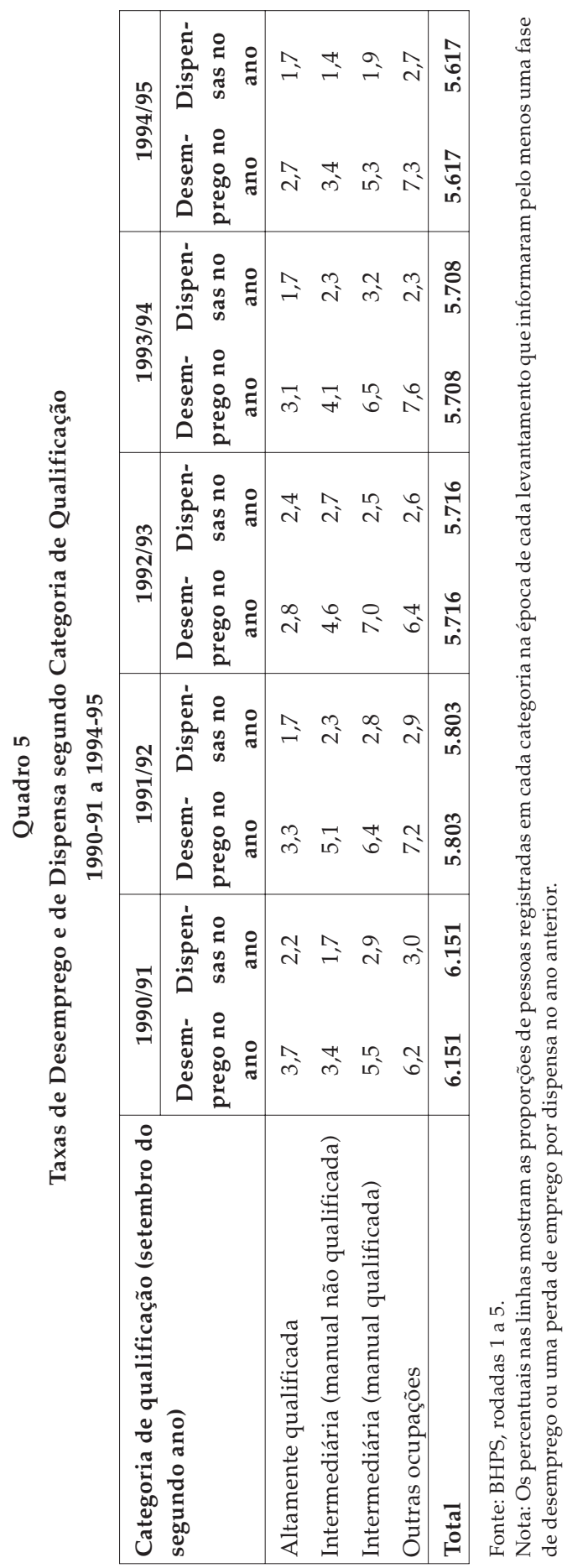


Reestruturação, Requalificação e Dispensas: Um Estudo da Dinâmica...

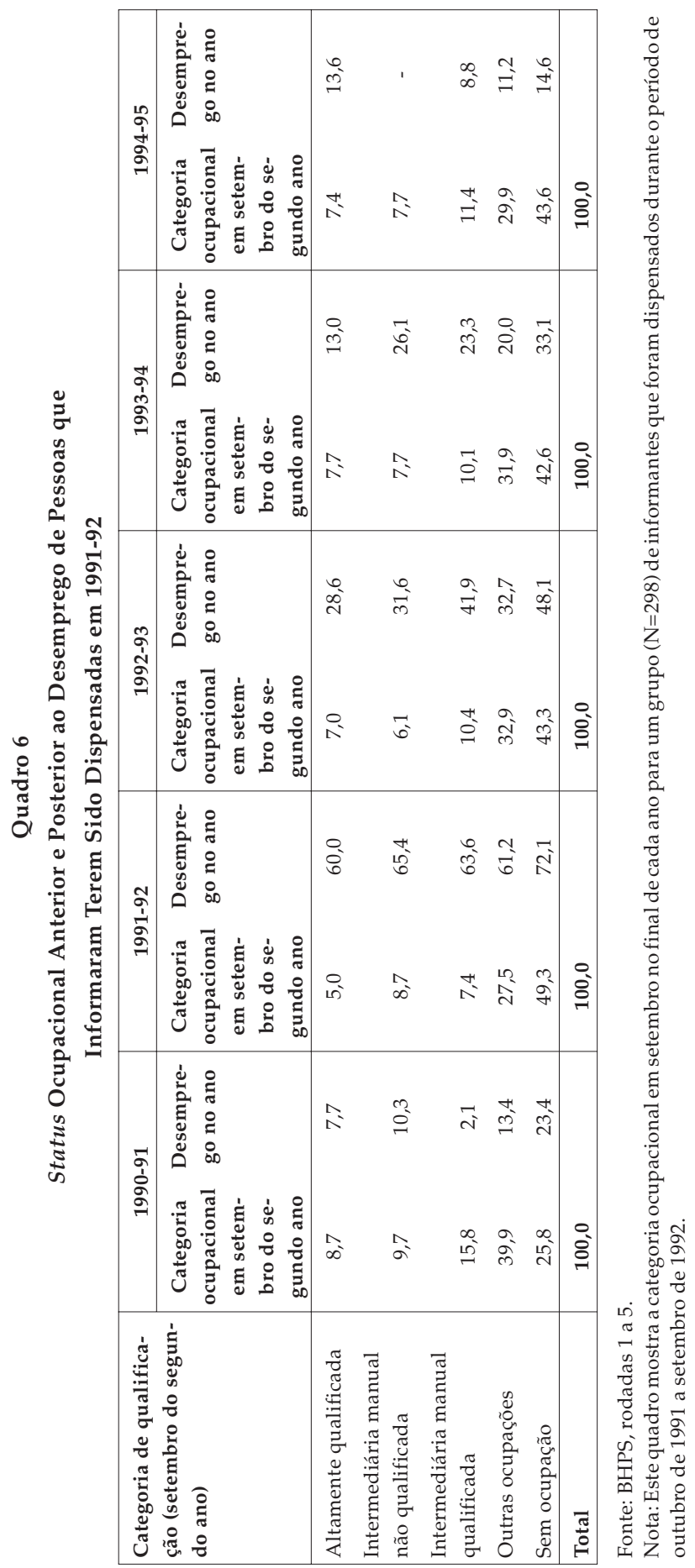


pensas e do desemprego sobre as pessoas em termos de desqualificação e de seus impactos sobre os rendimentos. Esta seção acompanha a dinâmica da mudança de modo mais agregado. Selecionando-se as pessoas que informaram terem sido dispensadas em 1991-92, o pico desse tipo de demissões após a recessão de 1990-91, é possível verificar as categorias ocupacionais em que elas ocorreram e as ocupações em que esses trabalhadores foram absorvidos. O Quadro 6 apresenta esses movimentos para as 298 pessoas do BHPS que informaram terem sido dispensadas entre 1991 e 1992 (o período entre rodadas da rodada 2). Examinando-se primeiro seu status ocupacional, pode-se verificar que mais de um quarto dessas pessoas não estavam empregadas um ano antes e que metade delas não tinha ocupação quando foram entrevistadas em 1992 (a entrevista que se seguiu imediatamente à dispensa informada). Esta alta taxa de não-emprego se mantém nas entrevistas sucessivas, indicando que uma reinserção estável no mercado de trabalho está se tornando um problema de longo prazo para os trabalhadores dispensados no período 1991-92.

Em termos das categorias ocupacionais em que surgem as dispensas e daquelas que reabsorvem os empregados demitidos, há indicações de deslocamentos de longo prazo. Proporções significativas das pessoas dispensadas em 1991-92 estão situadas no grupo de "outras ocupações" (40\%) e na categoria de ocupações manuais qualificadas (16\%). Como proporção de todos os que informaram uma ocupação em 1991, estes representam 54\% vindos de "outras ocupações" e 21\% das intermediárias qualificadas, refletindo basicamente a estrutura de qualificações em 1991. Já em 1995, 30\% desses trabalhadores dispensados tinham conseguido se reempregar em "outras ocupações" e $11 \%$ nas manuais qualificadas. Novamente, recalculando esses percentuais em termos dos que informaram estar empregados em 1995, eles representam $53 \%$ do grupo reempregado em outras ocupações e $20 \%$ nas manuais qualificadas. Assim, no geral, parece haver poucas evidências em termos agregados de uma "desqualificação" neste grupo. Contudo, o verdadeiro problema parece ser a subseqüente estabilidade no mercado de trabalho.

Em comparação com o Quadro 5, o desemprego informado por integrantes desse grupo, antes e depois dos anos em que foram dispensados, é consideravelmente mais elevado do que a média de cada uma das categorias ocupacionais. Com exceção da categoria das ocupações manuais qualificadas, a fase de desemprego anterior à dispensa 
informada no período 1990-91 é de três a quatro vezes maior do que a de todos os trabalhadores. Não surpreende então que essas taxas aumentem substancialmente no período 1991-92, quando essa amostra de trabalhadores dispensados foi selecionada, contudo as fases de desemprego continuam sendo altas nos anos subseqüentes. Embora o reduzido tamanho da amostra torne possível uma significativa variação na proporção, segundo categoria ocupacional, de trabalhadores reempregados em cada rodada subseqüente do estudo de painel, a magnitude e a coerência dessas diferenças, quando comparadas com o Quadro 5, deixam poucas dúvidas de que os trabalhadores dispensados em 1991-92 tiveram uma dificuldade consideravelmente maior de reintegrar-se ao mercado de trabalho.

\section{MOBILIDADE DOS RENDIMENTOS E MUDANÇA OCUPACIONAL}

Mudanças significativas da ocupação, como as identificadas na seção precedente, tendem a estar associadas com alterações na distribuição dos rendimentos. Esta seção explora essas relações, primeiro comparando as informações sobre rendimentos contidas na BHPS com aquelas coletadas pela LFS, e mostrando as relações entre as categorias amplas de qualificação e os ganhos. Finalmente são examinadas as mudanças de ano para ano na posição das pessoas empregadas dentro da distribuição geral de rendimentos.

\section{Informações sobre Rendimentos da BHPS e da LFS}

Antes de examinar pormenorizadamente a movimentação das pessoas dentro da distribuição dos rendimentos tal como definida por sua posição a cada rodada do BHPS, é interessante comparar a qualidade dessa informação com a das obtidas por um levantamento significativamente maior, a $\mathrm{QLFS}^{16}$. A Figura 3 compara as distribuições de rendimentos de homens e mulheres dessas duas fontes, considerando-se um ordenamento dos ganhos brutos semanais em intervalos de $£ 50$. No caso dos homens, a BHPS concentra-se excessivamente em pessoas com rendimentos entre $£ 151$ e $£ 200$ semanais e parece sub-representar as que ganham de $£ 350$ a $£ 400$ e de $£ 450$ a $£ 500$. Contudo, as diferenças são pequenas (no máximo o viés potencial das informações de rendimentos dos homens resulta em um excesso de $2 \%$ na categoria de $£ 151$ a $£ 200$ em comparação com o registrado pela LFS). No caso das mulheres, há uma boa correspondência entre as duas fontes. Portanto, pode-se concluir que as informações sobre rendimentos 
Peter Elias
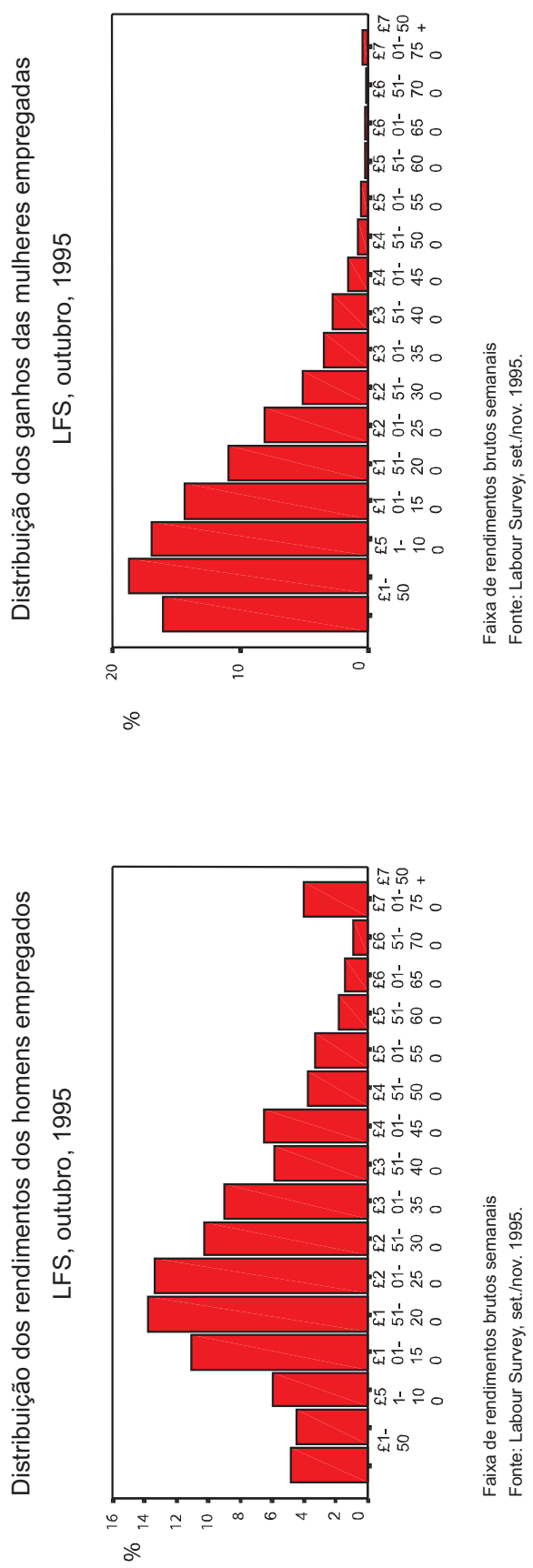
Reestruturação, Requalificação e Dispensas: Um Estudo da Dinâmica...

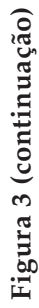
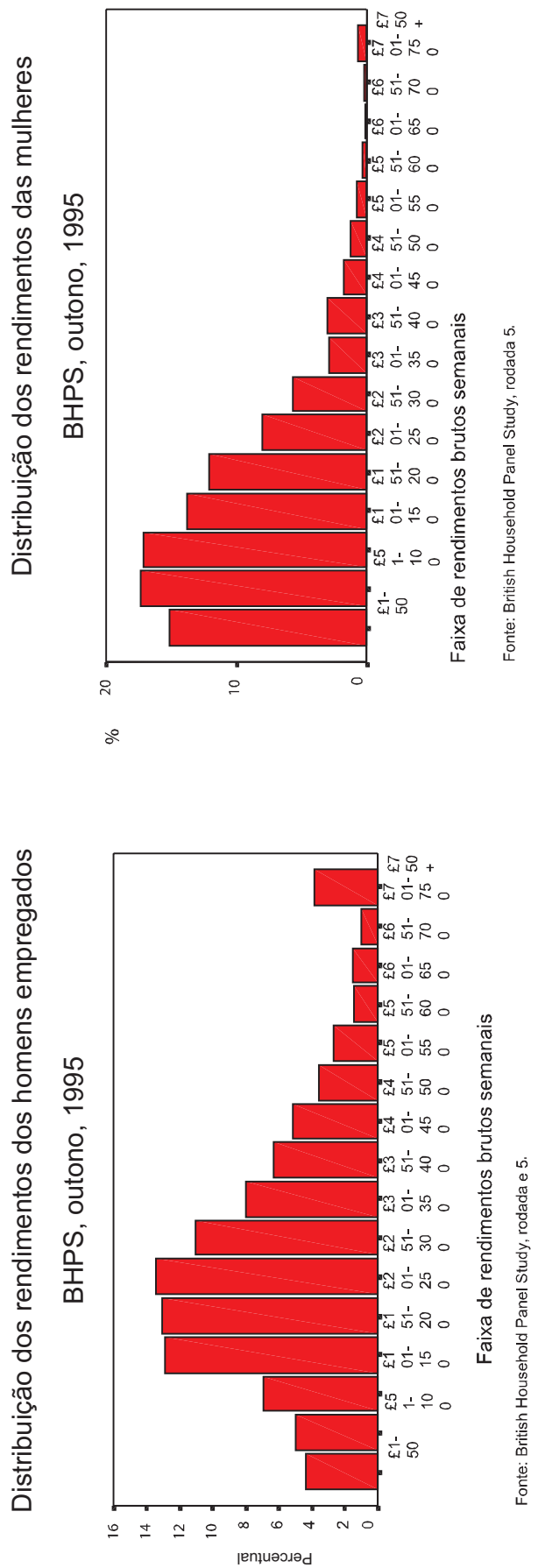
disponíveis na BHPS não mostram vieses grandes e significativos em relação à principal fonte de informações nacionais sobre rendimentos.

\section{Rendimentos e Categorias de Qualificação}

Algumas indicações da natureza da relação entre as quatro categorias de qualificação e os rendimentos podem ser obtidas analisando a Figura 4. Para elaborar esse gráfico de barras, as informações de salário mensal bruto da BHPS foram classificadas em decis, sendo que o decil 1 representa as pessoas que se situam nos $10 \%$ inferiores na distribuição de ganhos, e o decil 10 contém os $10 \%$ superiores. Por definição, cada decil inclui $10 \%$ de todas as pessoas cuja informação sobre rendimento mensal bruto habitual está disponível. Dentro de cada decil, distinguem-se as quatro categorias de qualificação.

Vemos na figura que o grupo de ocupações "altamente qualificadas" predomina nos 30\% superiores da distribuição de rendimentos. Já as "outras ocupações" predominam nos $40 \%$ inferiores da distribuição. As intermediárias, manuais qualificadas e não qualificadas, situam-se entre esses dois grupos em termos de rendimentos.

\section{Mobilidade dos Rendimentos, 1991-95}

Um dos aspectos mais significativos das mudanças na distribuição de renda no Reino Unido foi a ampliação das diferenças na distribuição

Figura 4

Distribuição do pagamento mensal habitual

Por categorias de qualificação, set. 1991

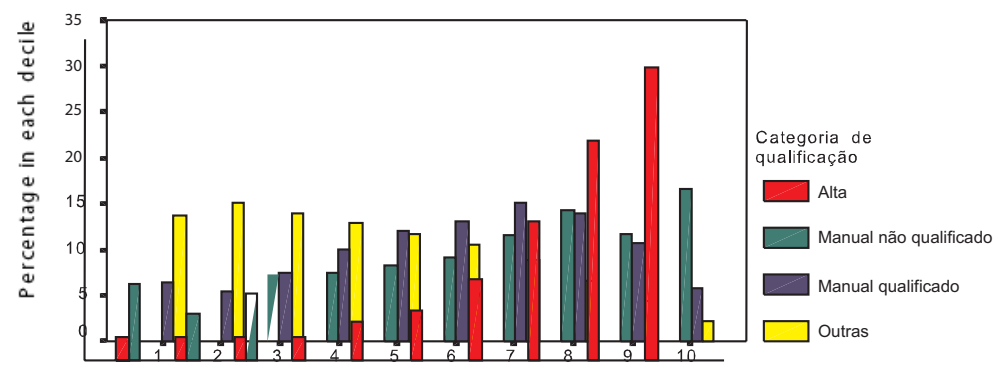

Decis de remuneração semanal Fonte: BHPS, rodada 1. 
no período pós-1979. Goodman e Webb (1994) mostram que, entre 1979 e 1991, os 20\% - 30\% de domicílios mais pobres não foram beneficiados pelo crescimento econômico. Comparações internacionais (Hills, 1995) mostram que poucos países desenvolvidos experimentaram tal aumento da dispersão, com exceção dos EUA onde aqueles que ganham menos receberam menos em termos reais do que os que estavam no extremo inferior da distribuição de renda dez anos antes.

Várias razões estão por trás das mudanças na distribuição da renda familiar no Reino Unido. Em parte, as rendas familiares no extremo inferior da distribuição não conseguiram aumentar em termos reais devido ao número crescente de pessoas que agora dependem de benefícios públicos (complementação de renda, aposentadoria, auxílio a famílias uniparentais) que são reajustados de acordo com os preços e não com os ganhos (DSS, 1993). Também é preciso levar em conta a crescente polarização dos domicílios entre os "ricos de emprego" e os "pobres de emprego" (Gregg e Wadsworth, 1994). Alguns analistas postulam que o aumento do número de pessoas com qualificações de mais alto nível (ensino médio completo e curso superior) e o adicional crescente atribuído à remuneração dessas qualificações contribuiu para aumentar a dispersão das rendas familiares (Gosling et alii, 1994; Schmitt, 1993). Embora esses fatores tenham provavelmente contribuído para a ampliação da dispersão, o principal fator associado a esse fenômeno é a ampliação das diferenças entre os rendimentos familiares. Em seu estudo sobre as mudanças na dispersão dos rendimentos masculinos, Gosling et alii (1994) mostraram que não houve praticamente mudança alguma na posição relativa do decil superior em relação ao inferior entre 1966 e 1980. De 1980 a 1992, os rendimentos dentro do decil inferior permaneceram quase estáticos em termos reais, enquanto o decil superior (e o mediano) registraram um aumento real de quase $30 \%$. Essa ampliação da dispersão dos rendimentos pode estar relacionada com as mudanças ocupacionais mostradas na seção anterior, já que o número de empregos na categoria "altamente qualificados" continuou em expansão enquanto as ocupações manuais qualificadas declinaram.

No exame da mobilidade ocupacional da seção "Qualificações e Mudança Ocupacional", foi tomado cuidado para assegurar que as ocupações fossem definidas em grupos suficientemente abrangentes para impedir que pequenos movimentos entre grupos ocupacionais relacionados fossem tomados como mobilidade ocupacional e, ainda 
assim, fossem suficientemente distintos para fins analíticos. No estudo da mobilidade dos rendimentos, existe esse mesmo problema de "limites". Os movimentos entre decis adjacentes podem ser devidos, por exemplo, a ligeiras flutuações nos ganhos dos que registram rendimentos próximos ao limite do decil. Como no caso das ocupações, essa mobilidade irrelevante pode ser ignorada concentrando-se o exame em três grandes segmentos da distribuição: os 30\% superiores, os $20 \%$ médios e os $30 \%$ inferiores ${ }^{17}$. Estabelecendo "zonas tampão" de $10 \%$ entre esses grupos, os movimentos de entrada e saída dessas categorias não estão associados a flutuações desprezíveis nos rendimentos, mas sim com alterações significativas dentro da distribuição dos ganhos.

A Figura 5 mostra o padrão de mobilidade dos rendimentos entre essas categorias no período de 1991 a 1995 segundo o BHPS. O primeiro ponto a observar na figura é que o hiato entre os que estão no topo da distribuição e os $30 \%$ que estão em sua base não continuou aumentando como ocorrera entre 1980 e 1991. A razão entre os ganhos médios dos 30\% superiores e dos 30\% inferiores manteve-se entre 7,4 em 1991 e 6,9 em 1995. Embora possa ser muito cedo ainda para concluir que a distribuição dos ganhos tenha começado a se estreitar, parece que ela já se estabilizou em comparação com as mudanças ocorridas na década de 80 .

Outro aspecto interessante dos padrões de mobilidade dos rendimentos mostrados na Figura 5 é a relativa estabilidade nos fluxos entre estas três "porções" principais da distribuição de ganhos. Os movimentos entre os $30 \%$ do topo e os $30 \%$ da base são muito pequenos e praticamente os mesmos em cada direção. Aproximadamente $2 \%$ de todas as pessoas empregadas se deslocam para cima e outros $2 \%$ descem a cada ano. De modo semelhante, os movimentos entre os $30 \%$ superiores e os $20 \%$ médios, e entre estes e os $30 \%$ inferiores são relativamente pequenos e estáveis de um ano para outro. Entre 4\% e 6\% das pessoas de cada grupo deslocam-se anualmente para a seção adjacente da distribuição. A Figura 5 também revela as diferenças entre essas categorias em termos de movimentos de entrada e saída da situação de emprego a cada ano. No caso das pessoas situadas nos $30 \%$ superiores da distribuição, de $8 \%$ a $10 \%$ entraram aí vindos do não-emprego no ano anterior, enquanto $12 \%$ a $14 \%$ ficam desempregadas. No outro extremo da distribuição, observa-se uma significativa movimentação entre emprego e não-emprego. De $23 \%$ a $27 \%$ passam do 
Reestruturação, Requalificação e Dispensas: Um Estudo da Dinâmica...

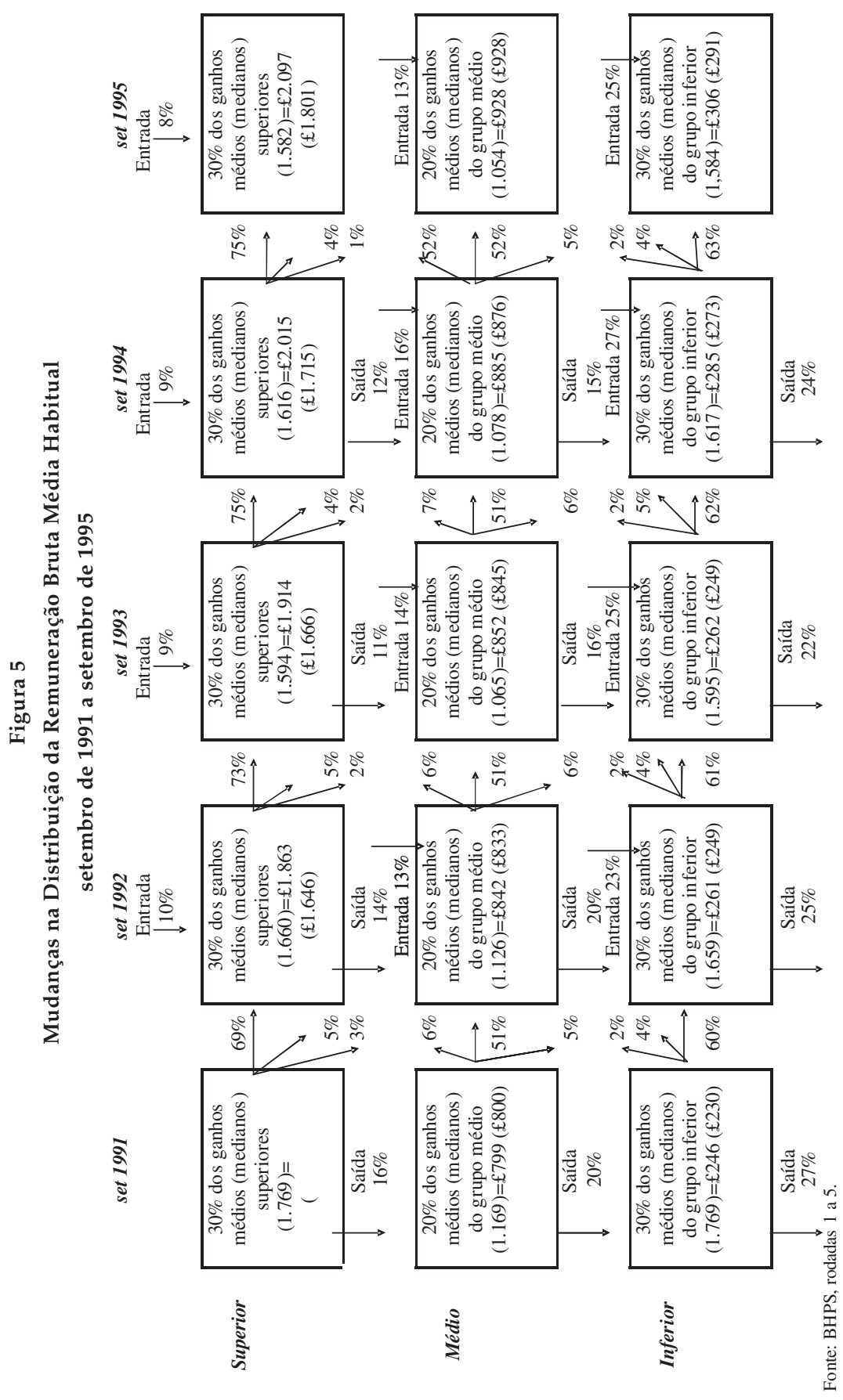


não-emprego para o emprego a cada ano, enquanto entre $22 \%$ e $27 \%$ percorrem o caminho inverso, corroborando verificações semelhantes de outros estudos (Jarvis e Jenkins, 1996; Ramos, 1996; Stewart e Swaffield, 1997).

\section{Mobilidade Líquida das Qualificações e Mudanças nos Rendimentos, 1991-95}

Na seção anterior, mostramos que um número pequeno mas significativo de pessoas sofreram mudanças substanciais na ocupação no período de 1991 a 1995, e, em conseqüência, subiram ou desceram na hierarquia ocupacional. Esta seção examina os resultados dessas alterações em termos das mudanças associadas nos rendimentos. A fazê-lo, respondemos às seguintes perguntas:

- A mobilidade ascendente das qualificações está associada a um aumento dos rendimentos, e vice-versa?

- As dispensas conduzem à desqualificação - uma descida na classificação hierárquica de qualificações usada neste estudo?

- Se as dispensas forem acompanhadas de desemprego, isso tem um efeito mais significativo sobre os rendimentos e as qualificações do que demissões não seguidas de uma fase de desemprego?

- Que outros fatores influenciam a mobilidade das qualificações e as alterações nos rendimentos - em particular, há diferenças entre homens e mulheres e entre diferentes grupos etários da população?

\section{Mobilidade líquida das qualificações}

Nem todas as pessoas entrevistadas pela BHPS estão presentes na força de trabalho a cada ano. Algumas não estavam empregadas na época da pesquisa, outras podem não ter ainda entrado na força de trabalho (caso dos jovens que estudam em tempo integral), outras podem ter se aposentado e há as que simplesmente preferiram não responder. Contudo, todos os informantes que trabalharam por algum tempo nos anos entre os levantamentos foram convidados a responder perguntas sobre os empregos tidos durante o ano, as razões para sair deles (se cabível), as fases de desemprego e as de inatividade econômica.

Para analisar as mudanças nas qualificações, a primeira tarefa foi a elaboração de indicadores de mobilidade líquida das qualificações no qüinqüênio abrangido pela BHPS até, incluso, a rodada 5. Isto foi fei- 
to adiantando a posição ocupacional do ano anterior ( 3 = ocupações altamente qualificadas, 2 = ocupações intermediárias e $1=$ outras ocupações), quando faltavam informações para algum ano e havia registro para o ano anterior, e atribuindo a posição ocupacional do período anterior nos casos em que a informação faltava no período mais atrasado, mas não nos anos seguintes. Levando em conta as diferenças das histórias ocupacionais resultantes e somando as diferenças, obtem-se uma medida da mobilidade líquida das qualificações de cada informante, no período $1991-1995^{18}$.

O Quadro 7 mostra a distribuição do indicador resultante de mudança líquida segundo gêneros e grupos etários. As mulheres apresentaram menos mudanças do que os homens no período, já os homens registraram maior mobilidade tanto no sentido ascendente quanto no descendente. Em conjunto, tanto homens quanto mulheres registram movimento ascendente dentro da hierarquia de qualificações. O grupo etário dos 25 aos 34 anos também mostra a maior proporção de informantes que registraram movimentos líquidos ascendentes na hierarquia de qualificações no período, enquanto o grupo mais idoso revelou a menor mobilidade.

Quadro 7

Mobilidade Líquida das Qualificações, segundo Gênero e Grupos Etários 1991-95

\begin{tabular}{|c|c|c|c|c|c|c|}
\hline \multirow{2}{*}{ Discriminação } & \multicolumn{5}{|c|}{ Mobilidade líquida das qualificações } & \multirow{2}{*}{$\begin{array}{c}\text { Total } \\
(=100 \%)\end{array}$} \\
\hline & -2 & -1 & 0 & 1 & 2 & \\
\hline Homens & 0,8 & 7,4 & 80,9 & 9,7 & 1,2 & 4.516 \\
\hline Mulheres & 0,5 & 4,6 & 87,2 & 5,9 & 1,7 & 4.203 \\
\hline \multicolumn{7}{|l|}{ Grupo etário } \\
\hline $16-24$ & 0,1 & 4,7 & 86,3 & 8,1 & 0,8 & 1.458 \\
\hline $25-34$ & 0,8 & 6,5 & 81,5 & 9,2 & 2,1 & 2.294 \\
\hline $35-44$ & 0,8 & 7,1 & 81,5 & 8,8 & 1,9 & 1.922 \\
\hline $45-54$ & 0,9 & 5,9 & 85,3 & 6,8 & 1,1 & 1.759 \\
\hline $55+$ & 0,9 & 5,4 & 87,2 & 5,4 & 0,9 & 1.286 \\
\hline
\end{tabular}

Fonte: BHPS, rodadas 1 a 5 .

Para ter alguma indicação dos efeitos separados de gênero e idade de vários aspectos econômicos, como continuidade do emprego, desemprego e dispensas, o indicador de mobilidade líquida das qualifica- 
ções foi usado como variável dependente em uma regressão de mínimos quadrados ordinários, com co-variáveis que incluíram um conjunto de variáveis binárias representando o grupo etário do informante (definido pela idade registrada em 1991), gênero, número de fases de desemprego sofridas pelo informante durante o período 1991-95, quantas vezes foi dispensado ${ }^{19}$, quantidade de vezes em que essas dispensas foram acompanhadas por uma fase de desemprego no mesmo ano, número de fases em que o informante esteve fora da força de trabalho e o número de empregos no período (onde um emprego é definido como mudança de empregador ou uma alteração significativa do tipo de trabalho feito para o mesmo empregador).

O Quadro A1 do Apêndice mostra o resultado dessa análise. Embora o poder explicativo total dessa regressão seja baixo $\left(R^{2}=0,091\right)$, o grande tamanho da amostra permite identificar algumas relações estatísticas significativas. Em especial, os efeitos da idade sobre a mobilidade líquida das qualificações mostram-se fortes. Os informantes jovens têm muito mais probabilidade de registrar um aumento líquido da qualificação, em parte porque os trabalhadores mais velhos têm menos oportunidades de aprimoramento ocupacional, mas também porque se verifica um movimento descendente líquido dentro da hierarquia de qualificação para os trabalhadores com 45 anos e mais. Uma variável binária separada para gênero mostra que não parece haver grandes diferenças entre homens e mulheres em termos de sua movimentação ocupacional líquida ascendente ou descendente dentro da hierarquia das qualificações no período 1991-95.

Nessa regressão, foram incluídas algumas variáveis que representam o histórico de trabalho das pessoas no período em pauta. Os informantes foram enquadrados nas categorias "nunca esteve economicamente inativo" no período 1991-95 (isto é, seu histórico mostra que sempre estiveram no mercado de trabalho) e "continuamente empregado" (nunca sofreram uma interrupção devida ou ao desemprego ou a inatividade econômica no período analisado). Nenhuma dessas variáveis apresentou uma associação estatística significativa como o movimento líquido das qualificações. O número de dispensas que o informante registrou no período 1991-95 foi incluído como uma variável de contagem. Verifica-se que isso teve um significativo impacto descendente na mobilidade ocupacional líquida. O número total de fases de desemprego registrada pelo informante e uma variável que representa as fases que se seguem a uma dispensa não se mostraram 
estatisticamente significativos. Como já foi observado, os efeitos da idade nos movimentos ocupacionais líquidos descendentes tornam-se significativos depois dos 45 anos e são fortes na faixa de mais de 55 anos.

Esses resultados indicam que não é o desemprego per se que resulta em um movimento ocupacional descendente, mas que as dispensas exercem poderosa influência descendente, quer o informante registre ou não uma fase de desemprego a seguir ou uma fase de desemprego por outras razões.

\section{Movimentos líquidos dos rendimentos, 1991-95}

Seguindo os mesmos métodos adotados para a análise da mobilidade das qualificações, foi definida a movimentação líquida entre decis da distribuição de rendimentos no período 1991-95 para um conjunto de 8.360 pessoas. Como foi mencionado na seção "Mobilidade dos Rendimentos, 1991-95", pode haver grande movimentação ascendente e descendente dentro dos limites dos decis que não resultam em mobilidade líquida dos rendimentos. Contudo, a Figura 6 mostra que um número significativo dos informantes que registraram ter auferido algum rendimento no período 1991-95 mostra uma movimentação líquida entre dois ou mais decis nesse qüinqüênio (aproximadamente $13 \%$ registraram um movimento ascendente de dois decis e mais, e $9 \%$ registraram o movimento inverso). A movimentação líquida total dos informantes nos cinco anos é ascendente, tanto no caso de homens quanto no de mulheres, refletindo o fato de que o movimento descendente dos rendimentos na proximidade do fim da vida de trabalho é menos significativo que o ascendente nos primeiros anos (Elias e Gregory, 1994).

Empregaram-se novamente técnicas de regressão para determinar os efeitos isolados do histórico de trabalho, idade e gênero sobre a mobilidade dos rendimentos. Os resultados apresentados no Quadro A2 do Apêndice mostram que o emprego continuado tem uma influência ascendente sobre a mobilidade dos rendimentos. As influências negativas estão associadas à idade, com a bem documentada influência descendente da idade sobre os rendimentos evidenciada pelas crescentes magnitude e significância dos coeficientes associados aos grupos etários mais altos (idem). O número de dispensas registradas por pessoa tem um efeito descendente muito forte sobre os ganhos, en- 
Figura 6

Mobilidade líquida dos rendimentos, 1991-95

(movimento líquido entre decis)

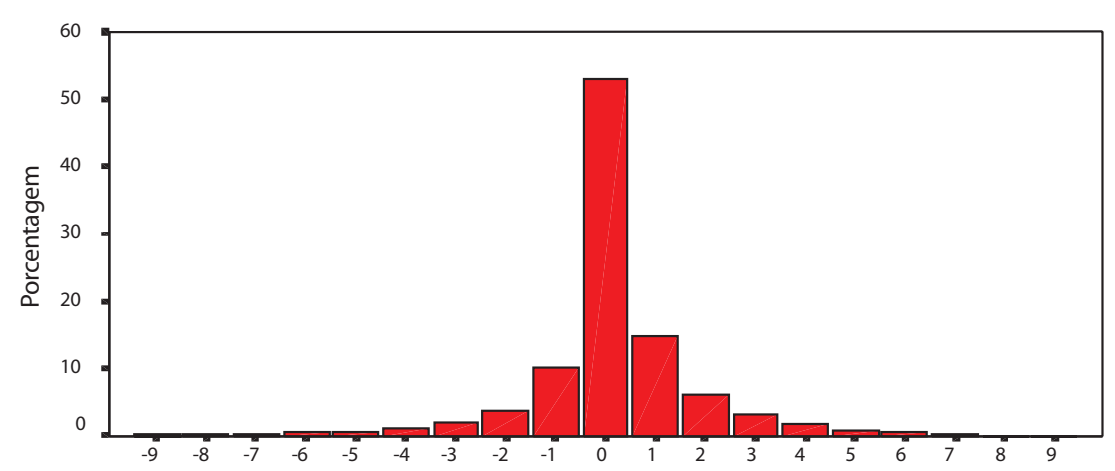

Mobilidade líquida dos ganhos (movimentos entre decis), 1991-95).

Fonte: BHPS, rodadas 1-5.

quanto as fases de desemprego, levado em conta o impacto das dispensas, mostram um efeito apenas marginal.

\section{Mobilidade das qualificações e mudanças nos rendimentos}

Até aqui analisamos a mobilidade da ocupação e dos rendimentos como fenômenos distintos. Contudo, está claro, como mostramos na seção "Rendimentos e Categorias de qualificação", que os movimentos ocupacionais podem redundar em grandes variações nos ganhos, especialmente quando esses movimentos atravessam os limites da classificação ampla de ocupações utilizada neste estudo. A relação entre mudança nas qualificações (movimento líquido ascendente ou descendente ao longo dos três patamares da hierarquia de qualificações) e a mobilidade dos rendimentos são examinadas adicionando a variável que define a movimentação líquida de qualificações no período 1991-95 ao conjunto de regressores mostrados no Quadro A2 do Apêndice.

Os resultados apresentados no Quadro A3 do Apêndice indicam uma associação forte e positiva entre movimentos ascendentes das qualificações e mobilidade ascendente dos rendimentos. É interessante observar que a ocorrência de dispensas ainda mostra um efeito forte e negativo sobre os rendimentos mesmo que o impacto de qualquer 
desqualificação devesse ser captado pela variável que representa a mobilidade líquida das qualificações. Esse resultado indica que as dispensas levam a uma desqualificação que provoca uma mobilidade descendente dos rendimentos, mas que a redução dos ganhos vai além daquela associada ao efeito de desqualificação.

\section{TREINAMENTO, DISPENSAS, DESQUALIFICAÇÃO E REQUALIFICAÇÃO}

O provimento de treinamento relacionado ao trabalho é muitas vezes apresentado como um mecanismo que pode auxiliar na reinserção dos que perderam seus cargos por dispensas, ou facilitar a mobilidade de pessoas para e em áreas em que o emprego se expande ${ }^{20}$. Contudo, o conhecimento dos impactos, no médio e no longo prazo, do treinamento, em termos de sua capacidade de promover a permanência nos empregos ou de facilitar a ida para empregos mais produtivos, é limitado. Arulampalam et alii (1997a) mostram que há uma relação positiva entre treinamento oferecido pelo empregador e os subseqüentes aumentos nos rendimentos, com base em uma análise dos dados sobre históricos de ganhos, emprego e treinamento de homens de 23 a 33 anos. Contudo, existem poucas indicações sobre o papel desempenhado pelo treinamento relacionado ao trabalho no reemprego de trabalhadores dispensados.

Embora as evidências sobre os efeitos de longo prazo do treinamento sejam poucas, há muitas informações sobre a ocorrência, a intensidade e a duração do treinamento. Vários estudos ${ }^{21}$ mostraram que o treinamento relacionado ao trabalho tende a estar associado a ocupações de nível mais alto, funcionalismo público e empregos nos setores de finanças e negócios. Além disso, a maior parte do treinamento, que tem duração relativamente curta, com exceção dos postos de aprendizes, tem lugar nos dois primeiros anos a partir da contratação e é muito mais comum entre os jovens.

Parece razoável pressupor que os dispensados são os que têm maior necessidade de treinamento relacionado ao trabalho e, como têm maior probabilidade de ter sido contratados há pouco tempo na fase posterior à dispensa, é muito mais provável que tenham recebido esse treinamento. Esta seção examina as informações da BHPS relativas à distribuição do treinamento relacionado ao trabalho, compara a tendência da incidência do treinamento com os dados existentes na LFS e distingue o treinamento dado aos que foram dispensados e aos que 
não o foram. Finalmente, o impacto do treinamento na mobilidade das qualificações e na evolução dos rendimentos líquidos é examinado, estudando-se o efeito dos indicadores de treinamento dentro do marco de referência formulado na seção anterior.

\section{Treinamento Relacionado ao Trabalho na BHPS e na LFS}

As informações sobre o treinamento relacionado ao trabalho da BHPS são coletadas como parte dos históricos de emprego das rodadas da pesquisa, por meio da pergunta: "Participou, desde 1을 de setembro do ano passado, de algum curso ou treinamento? Inclua programas de treinamento do governo, cursos da universidade aberta, cursos por correspondência e treinamentos no local de trabalho".

A distribuição de respostas a essa pergunta, em cada rodada da British Household Panel Study, segundo categorias ocupacionais, é apresentada no Quadro 8. No conjunto de todas as ocupações, a incidência do treinamento cai no período de 1990-93, voltando a subir ligeiramente em 1994-95.

Quadro 8

Treinamento Relacionado ao Trabalho Recebido desde Setembro do Ano Anterior à Entrevista, segundo Categoria de Qualificação

\begin{tabular}{|l|c|c|c|c|c|}
\hline \multirow{2}{*}{ Categoria de qualificação } & \multicolumn{5}{|c|}{$\begin{array}{c}\text { O informante recebeu treinamento relacionado } \\
\text { ao trabalho desde setembro do ano anterior }\end{array}$} \\
\cline { 2 - 6 } & $\mathbf{1 9 9 0 - 9 1}$ & $\mathbf{1 9 9 1 - 9 2}$ & $\mathbf{1 9 9 2 - 9 3}$ & $\mathbf{1 9 9 3 - 9 4}$ & $\mathbf{1 9 9 4 - 9 5}$ \\
\hline $\begin{array}{l}\text { Altamente qualificada } \\
\text { Intermediária (manual não }\end{array}$ & & 52,4 & 48,6 & 53,3 & 53,2 \\
qualificado) & 47,9 & 44,3 & 42,3 & 43,7 & 44,4 \\
$\begin{array}{l}\text { Intermediária (manual qua- } \\
\text { lificado) }\end{array}$ & 29,9 & 24,5 & 21,8 & 23,3 & 22,6 \\
$\begin{array}{l}\text { Outras } \\
\text { Total }\end{array}$ & 34,2 & 27,3 & 27,7 & 29,0 & 29,0 \\
Base (todos os empregados & 39,9 & 34,1 & 33,2 & 35,1 & 35,5 \\
durante o ano) & 6.151 & 5.803 & 5.716 & 5.708 & 5.617 \\
\hline
\end{tabular}

Fonte: BHPS, rodadas 1 a 5 .

As tendências registradas da incidência de treinamento medidas na LFS apresentaram problemas metodológicos. Um exame pormenorizado e tendências corrigidas das informações da LFS podem ser encontradas em Arulampalam et alii (1997b). No total, aproximadamen- 
te $15 \%$ dos empregados que responderam à LFS na faixa dos 16 aos 64 anos informaram ter recebido treinamento relacionado ao trabalho nas quatro semanas que antecederam a entrevista. Em vista disso, taxas anuais de $33 \%$ a $40 \%$ poderiam parecer baixas. Contudo, o treinamento é uma ocorrência de curta duração, sujeita a significativos erros de memória. Além disso, o treinamento tende a concentrar-se em determinados grupos de trabalhadores, sendo que alguns deles registram mais de uma dessas ocorrências no ano. Portanto, não seria de todo desarrazoado pressupor que as informações da BHPS relativas ao treinamento relacionado ao trabalho refletem uma incidência de treinamento coerente com os dados da LFS.

\section{Treinamento e Dispensas}

As informações sobre o treinamento relacionado ao trabalho da BHPS são coletadas em dois estágios. Primeiro, os trabalhadores empregados que respondem a pesquisa informam sobre ocorrências de formação/treinamentos relacionadas ao trabalho que tiveram lugar no ano anterior à pesquisa e que se referem ao emprego atual (aquele em que estão no momento da entrevista). Segundo, pede-se a todos os informantes que mencionem o treinamento relativo ao trabalho que tenha estado ligado a outros empregos tidos no mesmo período. Essa divisão permite distinguir a incidência de treinamento no emprego imediatamente posterior às dispensas, no caso dos trabalhadores que tenham conseguido outro emprego no momento da entrevista. Embora a comparação com os trabalhadores que não foram dispensados ${ }^{22}$ seja dificultada porque os dois grupos têm diferentes permanências no emprego, as comparações apresentadas no Quadro 9 indicam a medida em que o treinamento é oferecido a trabalhadores que voltam a se empregar após as dispensas.

A incidência de treinamento entre trabalhadores que conseguiram se reinserir no mesmo ano em que foram demitidos é, em geral, baixa. A proporção de treinamento recebido é de aproximadamente um terço da verificada entre os trabalhadores que não foram dispensados. A pequena base de alguns desses percentuais torna difícil determinar se a dispersão verificada nessas proporções é variação da amostra ou não. Não obstante a isso, dado que os trabalhadores reempregados têm uma permanência no emprego bem menor do que a de aqueles que não foram dispensados a cada ano, as informações apresentadas 


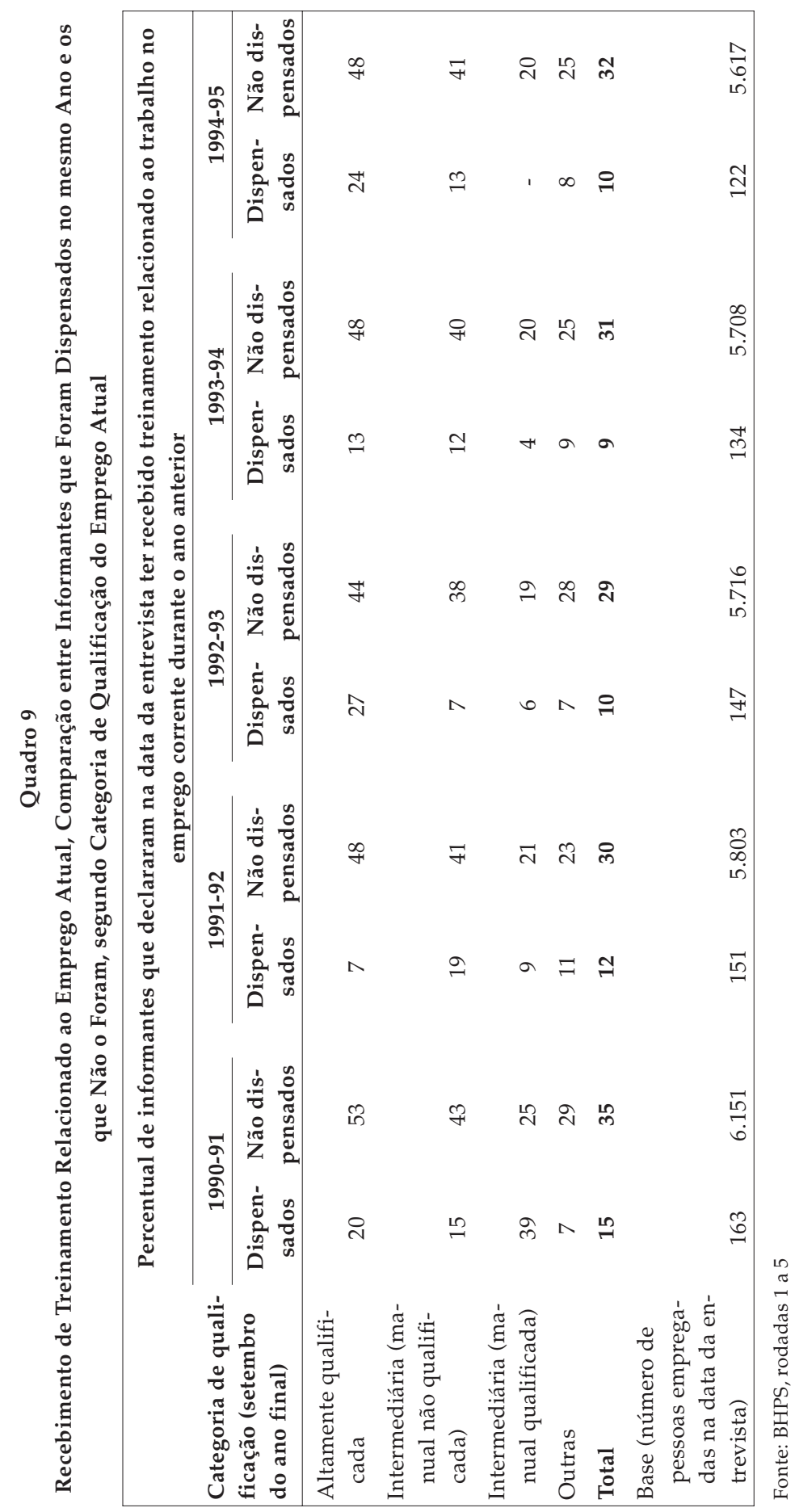


no Quadro 9 indicam que os trabalhadores reinseridos obtiveram uma quantidade significativa de treinamento relacionado ao trabalho.

\section{Treinamento e Mobilidade das Qualificações e dos Rendimentos}

A relação entre treinamento, dispensas, mobilidade das qualificações e rendimentos é aprofundada examinando-se a influência do treinamento dentro do marco de referência desenvolvido na seção "Mobilidade líquida das qualificações e mudanças nos rendimentos, 1991-95".

Elaboramos dois indicadores do recebimento de treinamento relacionado ao trabalho com vistas a analisar o impacto do treinamento sobre a mobilidade dos rendimentos. Primeiro, um indicador geral do recebimento de treinamento relacionado ao trabalho mede se a pessoa recebeu, ou não, treinamento em algum momento durante o período 1991-95. Segundo, no caso das pessoas que conseguiram um novo emprego após qualquer dispensa em dado ano, foi elaborada uma variável que mede se a pessoa recebeu, ou não, algum treinamento no emprego conseguido logo após a dispensa.

Os resultados dessa análise aparecem no Quadro A4 do Apêndice. O chamado "indicador geral" de treinamento - uma variável binária codificada como 1 se o informante recebeu qualquer treinamento relacionado ao trabalho no período em que fez parte da força de trabalho entre 1991 e 1995 - está correlacionado com movimentos líquidos ascendentes na distribuição de ganhos. O efeito é encontrado depois de controlar quaisquer outras influências que pudessem estar correlacionadas tanto ao treinamento quanto à variação dos rendimentos, especialmente mudanças ocupacionais líquidas registradas no mesmo período. Em outras palavras, os trabalhadores que recebem treinamento relacionado ao trabalho têm mais possibilidade de registrar uma ascensão, em termos líquidos, na distribuição de rendimentos. Não se verificou nenhuma associação significativa entre "treinamento após dispensas" e mobilidade nos ganhos, indicando que o treinamento não protege os trabalhadores dispensados das conseqüências econômicas negativas no longo prazo decorrentes das dispensas. 


\section{SUMÁRIO}

Este estudo utilizou o crescente acervo de informações sobre a dinâmica do mercado de trabalho, obtido pela British Household Panel Study, que agora está disponível. Com base nos dados das cinco rodadas do estudo realizado no período 1991-95, a pesquisa apresentada neste artigo examina quatro aspectos inter-relacionados das mudanças na estrutura do mercado de trabalho britânico: dispensas, desemprego, mobilidade ocupacional e variação dos rendimentos.

Foi tomado muito cuidado para assegurar que os dados do painel fossem, e continuassem sendo, representativos da população britânica. Isso foi feito comparando-se os dados do BHPS com informações semelhantes de diversas fontes, como o Censo Demográfico de 1991 e a LFS de 1991 a 1995. Em termos dos indicadores de estrutura ocupacional, rendimentos e fonte de informações sobre as dispensas, verifica-se que os dados da BHPS replicam bem esses mesmos indicadores estruturais do mercado de trabalho encontrados em outras fontes de dados mais amplas.

O principal foco desta pesquisa são os impactos das dispensas no longo prazo - definidos como perda involuntária de emprego por razões associadas às mudanças nas circunstâncias econômicas do empregador. Diferentemente das demissões voluntárias, as dispensas podem ser uma das ocorrências mais perturbadoras que os trabalhadores enfrentam, mas muito pouco é conhecido sobre os impactos dessa ocorrência no longo prazo. As taxas de dispensas aumentam nas recessões e diminuem nos períodos de recuperação econômica. Durante a lenta recuperação que se seguiu à recessão de 1990-91, o número anual de dispensas na Grã-Bretanha caiu de cerca de 1,5 milhões para três quartos de milhão em 1994-95. Em relação ao número de novos pedidos de benefícios-desemprego registrados a cada ano, os trabalhadores dispensados representaram menos de um quarto de todos os pedidos em 1991, caindo para cerca de $10 \%$ dos novos pedidos em 1994-95.

Para estudar as mudanças na estrutura ocupacional, utilizou-se uma classificação de ocupações que tenta identificar grupos de ocupação que estão em uma posição intermediária entre empregos que exigem um investimento significativo em escolaridade, treinamento e/ou experiência de trabalho para se alcançar a competência e aqueles para os quais os requisitos de escolaridade, além dos anos de ensino obri- 
gatórios, e de treinamento/experiência de trabalho são de um ano ou menos. Esse grupo de ocupações, desenvolvido em um estudo relacionado voltado à progressão das qualificações e ao treinamento, foi subdividido entre aquelas que são ocupações manuais qualificadas tradicionais e um grupo intermediário de atividades manuais não qualificadas. A lógica dessa subdivisão torna-se clara quando se examina a evolução dessas categorias ocupacionais no período de 1981 a 1995. Tanto no caso dos homens como no das mulheres, a categoria de ocupações altamente qualificadas aumentou rapidamente no decorrer de tempo, passando de cerca de 3\% de todos os empregos entre 1981 e 1991, para quase a mesma coisa entre 1991 e 1995. Como proporção de todo o emprego masculino ou feminino, a categoria de baixa qualificação caiu no período nos dois casos. Este é, isoladamente, um resultado interessante, dado que há uma opinião amplamente aceita segundo a qual está em curso um processo de desqualificação na economia britânica e que o aumento dos empregos de baixa qualificação, mal remunerados, contribuíram para a amplicação das diferenças na distribuição de rendimentos no período posterior a 1979.

As ocupações intermediárias manuais qualificadas estão em contínuo declínio, caindo de cerca de $2 \%$ de todos os empregados entre 1981 e 1991. Surpreendentemente, a taxa de queda aumentou no período 1991-95, caindo mais 3,5 pontos percentuais. No caso das ocupações intermediárias manuais não qualificadas, ocorreu o inverso, verificando-se no período 1981-91 um aumento, no caso de homens e mulheres, e uma fase de estabilidade de 1991 a 1995.

Essas mudanças ocorrem de várias formas. No caso do grupo de ocupações "altamente qualificadas" (postos gerenciais de alto nível e ocupações que exigem curso superior), o crescimento foi alcançado por meio de uma queda no número de trabalhadores que saem dessa categoria para outros grupos ocupacionais. Quanto ao grupo de ocupações "intermediárias manuais não qualificadas", a estabilidade no período 1991-95 oculta uma considerável mobilidade de entrada e saída desse grupo. Aproximadamente 10\% de todos os trabalhadores dessa categoria passam para o grupo altamente qualificado a cada ano, e uma proporção semelhante vai para as "outras ocupações" que requerem menos qualificação, sendo que esses fluxos são substituídos por trabalhadores que se movem em direção oposta. No caso de ocupações intermediárias manuais qualificadas, a queda parece ser devida principalmente a um fluxo líquido de trabalhadores que pas- 
sam para a situação de não-emprego e por outros que passam a categoria de "outras ocupações" menos qualificadas.

As relações entre dispensas, desqualificação potencial e desemprego são aprofundadas acompanhando-se o status anterior e posterior à demissão no período 1991-92. A maioria dos que formam este grupo estava empregada em ocupações intermediárias manuais qualificadas e em "outras", no início do período. Subsequentemente, até 1995, $40 \%$ a $50 \%$ dos informantes declararam não ter emprego à época de cada rodada. Durante um período de dois anos após as dispensas, a ocorrência de desemprego é também muito mais elevada do que antes das dispensas. Parece, então, que aqueles que foram dispensados podem estar concorrendo ao reemprego com outros candidatos mais jovens e possivelmente melhor qualificados, sendo muitas vezes exacerbado pelo fato de os trabalhadores dispensados terem qualificações e experiência de trabalho que não são, quase por definição, escassas.

Embora seja possível antecipar as dificuldades para a reinserção dos trabalhadores dispensados no mercado de trabalho, esse exame não revela toda a extensão do impacto subseqüente das dispensas no status ocupacional e nos rendimentos. Para tanto, utilizamos os registros das entrevistas de todos os informantes da BHPS que já trabalharam - cerca de 8.400 pessoas - e os examinamos buscando movimentos líquidos sistemáticos de subida e descida ao longo da hierarquia de qualificações e de rendimentos. Com base nesses dados, pode-se mostrar que não é tanto a ocorrência de desemprego que traz consigo a desqualificação e a queda de rendimentos, mas sim as dispensas. Além disso, verifica-se que esse tipo de demissão influencia negativamente os rendimentos de maneira tanto direta quanto indireta a partir da desqualificação subseqüente.

O papel desempenhado pelas dispensas nesse processo de mudança ocupacional foi examinado com certa minúcia. Ser dispensado implica mais do que a mera perda de um emprego. Quando os trabalhadores são dispensados, o que está em pauta é uma redução na demanda de suas qualificações e de sua experiência. A reinserção, como mostra este estudo, pode ocorrer quando se aceita trabalho alternativo a salários inferiores aos ganhos de antes da dispensa. O trabalho apresenta informações sobre a extensão da falta de trabalho, da desqualificação e da redução dos rendimentos dos que passaram por dispensas. Esse 
tipo de desligamento é o mais importante fator isolado associado à mobilidade ocupacional líquida descendente no período 1991-95. Essa desqualificação não apenas traz em sua esteira movimentos declinantes dos rendimentos, mas carrega consigo um movimento de redução salarial subseqüente associado a essas dispensas e à falta de qualquer mudança ocupacional relevante.

Finalmente, este estudo visou verificar a ocorrência ou a ausência de evidências que sugiram como os piores impactos das dispensas poderiam ser amenizados de alguma forma. Em particular, o treinamento relacionado ao trabalho poderia auxiliar os trabalhadores afetados pelas dispensas a adquirir novas qualificações e/ou modificar as já existentes. De modo coerente com informações similares coletadas na LFS, os que responderam à BHPS relataram vários casos de treinamento relacionado ao trabalho e se verificou que os que recebem esse treinamento têm maior probabilidade de ascender na distribuição de rendimentos. Contudo, esse resultado talvez apenas confirme o que já se sabe sobre o treinamento relacionado ao trabalho - que ele tende a concentrar-se em áreas em que existe algum tipo de estrutura de carreira e atingem principalmente os trabalhadores jovens. Para aprofundar essa análise, o estudo investigou os trabalhadores dispensados que receberam treinamento no emprego seguinte à demissão, tratando de ver se esse treinamento contribuiu para que os reempregados fugissem ao impacto negativo sobre a sua posição dentro da escala de rendimentos associada a esse tipo de demissão. Não foram encontradas indicações que sugerissem que esse treinamento pudesse melhorar as perspectivas de trabalho das pessoas afetadas ou até amenizar os piores efeitos das dispensas.

Os resultados desta pesquisa são especialmente preocupantes para os que estão envolvidos com as implicações, em termos de políticas públicas, da reestruturação do mercado de trabalho. Se o período pesquisado tivesse sido um de entrada na recessão, os impactos negativos observados não teriam sido muito surpreendentes. Mas trata-se de um período de recuperação econômica lenta e sustentada. A "reestruturação" do mercado de trabalho é um processo que não se limita às recessões. O crescimento sustenta-se no segmento "altamente qualificado" do mercado de trabalho e observa-se a continuação da queda no emprego das atividades pouco qualificadas, apesar do contínuo aumento no emprego de mulheres em ocupações de tempo parcial. No mercado de trabalho britânico, essas tendências, embora não 
bem reconhecidas, são parte do movimento de mais longo prazo em favor de empregos de mais alto nível. Contudo, entre esses dois polos há um grupo de ocupações denominadas intermediárias, muitas vezes consideradas como uma "passagem" entre os empregos de baixa qualificação e os de nível mais alto. Subdividindo esse segmento em ocupações manuais qualificadas e não qualificadas, mostramos que as ocupações qualificadas tradicionais registram um estágio de continuado declínio que possivelmente se acelera. Embora em todos os segmentos ocupacionais se verifiquem dispensas, esse grupo registra as mais altas taxas de dispensas e de desemprego em comparação com os segmentos de alta qualificação e de atividades intermediárias manuais qualificadas. Em termos de capacidade de propiciar progressão das qualificações, as ocupações intermediárias manuais qualificadas parecem ter poucas chances.

Talvez o resultado mais surpreendente seja relativo à situação que se segue às dispensas. Os impactos sobre os que passaram por esse processo são negativos e de efeitos duradouros. Entre esses efeitos, podemos citar redução nos rendimentos, desqualificação, desemprego e subseqüente instabilidade no mercado de trabalho. Na definição de um grupo a ser focalizado nas intervenções no mercado de trabalho, basta olhar para os que foram dispensados.

(Recebido para publicação em janeiro de 2004)

(Versão definitiva em agosto de 2004)

\section{NOTAS}

1. Pessoas continuamente desempregadas há 12 meses ou mais.

2. A queda de $7 \%$ na produção industrial, registrada na década de 90 , indicava a recessão mais aguda e profunda no mercado de trabalho do Reino Unido desde 1979.

3. Outras formas de ajustamento incluem restrições à realização de horas-extra, redução da jornada de trabalho, suspensão temporária do contrato de trabalho, ajusta- 
mentos no processo de recrutamento, congelamento das remunerações ou cortes no entesouramento de mão-de-obra.

4. A lista de razões dentre as quais os informantes selecionam sua resposta é a seguinte: "parei de trabalhar por motivo de saúde; achei um emprego melhor; aposentadoria; maternidade; fui dispensado; fui demitido/mandado embora; para cuidar das crianças/do lar; outros motivos; fui promovido; fim do prazo de um contrato temporário; tive que deixar o emprego para cuidar de outra pessoa (não filhos)".

5. Em Potter (1990) encontra-se um exame da sazonalidade nas séries trimestrais de dados sobre dispensas da LFS e pormenores do método de construção de uma série anualizada.

6. Os dados anuais da LFS registram um pico das dispensas nos três meses anteriores segundo trimestre de 1991, com 391 mil dispensas.

7. Se a amostra da BHPS fosse uma amostra aleatória simples, o intervalo de confiança de $95 \%$ para o percentual de dispensas registradas seria de \pm 106 pontos percentuais. Efeitos do desenho da amostra ampliam esse intervalo.

8. Esta é uma definição bastante ampla do desemprego "relacionado à despedida" (redundancy related), decorrente do fato de que os acontecimentos imediatamente posteriores à dispensa podem não refletir adequadamente seus efeitos, especialmente quando os trabalhadores dispensados dão um tempo antes de começar a procurar emprego ou em casos em que um emprego de prazo limitado muito curto é aceito logo após o desligamento.

9. Medido como a entrada na situação de requerente de benefícios.

10. Por exemplo, Merseyde, o Nordeste, Strathclyde.

11. Esta metodologia empregada por Jacobson, Lalonde e Sullivan (1993) pode acabar por subestimar o efeito das dispensas, dado que se apóia em informações relativas a despensas e o subseqüente novo emprego de funcionários de uma empresa em uma localização específica.

12. Office for Population Censuses and Survey (1990).

13. Uma descrição da evolução destes agrupamentos, da mobilidade entre eles nos períodos de 1976-83 e de 1983-94 e da auto-avaliação sobre competências na leitura, espreita, fala, uso de ferramentas, construção, computação, atendimento, orientação, aconselhamento, venda e organização de pessoas integrantes desses grupos é encontrada em Elias e Bynner (1996).

14. Destas três fontes, a BHPS é a que tem a menor amostra. A maior diferença observada entre a BHPS e as outras estimativas de estrutura de qualificação da população empregada é de 1,4\%, dentro dos limites de um intervalo de confiança de $95 \%$ para a proporção estimada.

15. Em outras palavras, a entrada na área ocupacional daqueles vindos do setor educacional pode ser menor que a saída associada às aposentadorias.

16. As informações sobre rendimentos são coletadas apenas entre os que estão saindo da rotação dos cinco períodos trimestrais de rotação previstos no desenho da amostra da LFS. Os dados para o terceiro trimestre de 1995 compreendem 4.202 empregados e 4.476 empregadas que forneceram as informações sobre rendimentos. Isso é comparado às informações de 2.673 homens e 2.552 mulheres empregados que forneceram dados para a rodada 3 da BHPS, em setembro de 1995. 
17. O interesse dos 30\% inferiores da distribuição de rendimentos decorre de ser esse o chamado "limiar da decência" (decency threshold) definido pelo Conselho Europeu.

18. Um exemplo será esclarecedor. Imagine quatro trabalhadores com os seguintes históricos ocupacionais.

\begin{tabular}{l|c|c|c|c|c}
\hline Trabalhador & $\begin{array}{c}\text { rodada } \\
191-\text { nov }\end{array}$ & $\begin{array}{c}\text { rodada } \\
191-\text { nov }\end{array}$ & $\begin{array}{c}\text { rodada } \\
191-\text { nov }\end{array}$ & $\begin{array}{c}\text { rodada } \\
191-\text { nov }\end{array}$ & $\begin{array}{c}\text { rodada } \\
191-\text { nov }\end{array}$ \\
\hline $\mathrm{i}$ & - & - & 1 & - & 2 \\
$\mathrm{j}$ & 2 & - & - & - & - \\
$\mathrm{k}$ & - & - & 3 & - & 2 \\
$\mathrm{l}$ & 3 & - & 1 & - & 3 \\
\hline
\end{tabular}

Transferindo para a frente a posição ocupacional do ano anterior e levando para trás a posição do ano seguinte teremos:

\begin{tabular}{lcccccc}
\hline Trabalhador & $\begin{array}{c}\text { rodada } \\
\text { 191- nov }\end{array}$ & $\begin{array}{c}\text { rodada } \\
191-\text { nov }\end{array}$ & $\begin{array}{c}\text { rodada } \\
191-\text { nov }\end{array}$ & $\begin{array}{c}\text { rodada } \\
191-\text { nov }\end{array}$ & $\begin{array}{c}\text { rodada } \\
191-\text { nov }\end{array}$ & $\begin{array}{c}\text { Mobilida- } \\
\text { de líquida }\end{array}$ \\
\hline $\mathrm{i}$ & 1 & 1 & 1 & 1 & 2 & +1 \\
$\mathrm{j}$ & 2 & 2 & 2 & 2 & 2 & 0 \\
$\mathrm{k}$ & 3 & 3 & 3 & 3 & 2 & -1 \\
$\mathrm{l}$ & 3 & 3 & 1 & 1 & 3 & 0 \\
\hline
\end{tabular}

A mobilidade líquida é calculada diferenciando as mudanças resultantes de ano para ano e somando as diferenças.

19. No período 1991-95, 2,338 (26.8\%) dos 8,710 informantes da BHPS que estiveram no mercado de trabalho por algum tempo registraram fases de desemprego. Desses $657,7,59 \%$ informaram ter sido dispensados pelo menos uma vez no mesmo período. A distribuição cross distribution dessas fases é apresentada abaixo.

\begin{tabular}{l|r|r|r|r|r|r}
\hline \multirow{2}{*}{ Número total de desempregados } & \multicolumn{6}{|c}{ Número total de dispensas seguidas por } \\
\cline { 2 - 7 } 0 & \multicolumn{1}{|c|}{0} & 1 & 2 & 3 & 4 & Total \\
\cline { 2 - 7 } 1 & 6381 & - & - & - & - & 6381 \\
2 & 1017 & 316 & - & - & - & 1333 \\
2 & 380 & 168 & 20 & - & - & 568 \\
3 & 154 & 62 & 23 & 2 & - & 241 \\
4 & 79 & 32 & 17 & 2 & 1 & 131 \\
5 & 51 & 11 & 2 & 1 & -1993 & 65 \\
\hline
\end{tabular}

20. Ver, por exemplo, Britton (1997:45-46).

21. Em Arulampalam et alii encontra-se uma revisão. 
22. Os trabalhadores que estão empregados na época de cada entrevista e que não informaram ter sido dispensados nos anos anteriores.

\section{REFERÊNCIAS BIBLIOGRÁFICAS}

ACKUM, Agell S. (1991), "Youth Unemployment, Labour Market Programs and Subsequent Earnings". Scandinavian Journal of Economics, vol. 93, nº 4, pp. 531-543.

ARULAMPALAM, Wiji., BOOTH, Alison L. e ELIAS, Peter. (1997a), “Work-related Training and Earnings Growth for Young Men in Britain". Research in Labor Economics, vol. 16, pp. 119-147.

. (1997b), "The Incidence and Duration of Work-related Training in the UK". University of Warwick. Manuscrito.

ATKINSON, Anthony B. (1993), “What is Happening to the Distribution of Income in the UK?" STICERD Welfare State Programme Discussion Paper WSP/106. London, London School of Economics.

BLANCHFLOWER, David G. (1991), "Fear, Unemployment and Pay Flexibility". Economic Journal, vol. 101, no 406, pp. 483-496.

BRITTON, Andrew. (1997), "Full Employment in a Market Economy", in J. Philpott (org.), Working for Full Employment. London, Routledge.

DE LA RICA, Sara. (1995), “Evidence of Pre-separation Earnings Losses in the Displaced Worker Survey". Journal of Human Resources, vol. 30, no 3, pp. 610-621.

DEPARTMENT OF SOCIAL SECURITY - DSS. (1993), Households Below Average Income: A Statistical Analysis, 1979 - 1990/91. London, HMSO.

ELIAS, Peter. (1995), "Social Class and the Standard Occupational Classification", in D. Rose (org.), A Report on Phase 1 of the ESRC Review of the OPCS Social Classifications. Swindon, Economic and Social Research Council.

. (1996), The Development and Structure of Long-Term Unemployment in Britain. Trabalho apresentado no workshop Long-Term Unemployment: A European Problem. Landesakademie für Struktur und Arbeit, Genshagen, Brandenburgo, Alemanha, 11-12 de junho.

. (1997), The Effect of Unemployment Benefit and Income Support on the Labour Force Participation of Partners. Institute for Employment Research, University of Warwick. Manuscrito.

e BYNNER, John. (1996), “'Individuals' Skills Progression: Patterns of Mobility from Lower to Higher Levels of Employment". Research Studies RS44. London, Department for Education and Employment.

ELIAS, Peter e GREGORY, M. (1994), “The Changing Structure of Occupations and Earnings in Great Britain, 1975-90". Research Paper, no 27. London, Department of Employment.

GOODMAN, Alissa e WEBB, Steve. (1994), "For Richer and Poorer: The Changing Distribution of Income in the United Kingdom, 1961-1991". Commentary, no 42, Institute for Fiscal Studies, London, IFS. 
GOSLING, Amanda, MACHIN, Steve e MEGHIR, Costas. (1994), “What Has Happened to Wages?" Commentary, no 43, Institute for Fiscal Studies,London, IFS.

GREEN, Anne E. (1994), The Geography of Poverty and Wealth: Evidence on the Changing Spatial Distribution and Segregation of Poverty and Wealth from the Census of Population, 1991 and 1981. Coventry, University of Warwick, Institute for Employment Research.

GREGG, Paul e WADSWORTH, Jonathan. (1994), More Work in Fewer Households. National Institute for Economic Research, London. Manuscrito.

GREGORY, Mary e JUKES, Robert. (1997), The Effects of Unemployment on Subsequent Earnings: A Study of British Men, 1984-1994. Relatório de pesquisa, Department for Education and Employment, London.

HILLS, John. (1995), Joseph Rowntree Foundation Inquiry into Income and Wealth: A Summary of the Evidence. York, Joseph Rowntree Foundation (vol. 2).

JACOBSON, Louis S., LALONDE, Robert e SULLIVAN, Daniel G. (1993), “Earnings Losses of Displaced Workers". American Economic Review, vol. 83, no 4, pp. 685-709.

JARVIS, Sarah e JENKINS, Stephen P. (1995), “Do the Poor Stay Poor? New Evidence about Income Dynamics from the British Household Panel Study". Occasional Paper, $\mathrm{n}^{\circ}$ 95-2. ESRC Research Centre on Micro-social Change, Colchester, University of Essex.

. (1996), "Changing Places: Income Mobility and Poverty Dynamics in Britain" Working Papers, nº 96-19, ESRC Research Centre on Micro-social Change, University of Essex

Office for National Statistics — ONS. (1997), Social Trends, 1997. Londres: HMSO.

Office of Population Censuses and Surveys. (1990), Standard Occupational Classification: Volume 1. London, HMSO.

POTTER, Jonathan. (1996), “Annualised Redundancy Data: Calculated from the Labour Force Survey". Labour Market Trends, julho, pp 239-332.

RAMOS, Xavier. (1996), UK Earnings Inequality and Earnings Mobility: Evidence from the BHPS, 1991-94. University of Essex, ESRC Research Centre on Micro-social Change. Manuscrito.

RUHM, Christopher J. (1991), “Are Workers Permanently Scarred by Displacements?" American Economic Review, vol. 81, nº 1, pp. 319-324.

SCHMITT, John. (1993), "The Changing Structure of Male Earnings in Britain, 1974-88". Discussion Paper, no ${ }^{\circ}$ 122, London, Centre for Economic Performance, London School of Economics.

SLY, Frances, Price, A. e RISDON, A. (1997), “Women in the Labour Market: Results from the Spring 1996 Labour Force Survey". Labour Market Trends, março, pp 99-120.

STEWART, Mark e SWAFFIELD, Joanne. (1997), Low Pay Dynamics and Transition Probabilities. Coventry, Departamento de Economia, University of Warwick. Manuscrito.

VAN AUDENRODE, M. e LEONARD, Jonathan. (1995), “The Duration of Unemployment and the Persistence of Wages". Discussion Paper, $\mathrm{n}^{\mathrm{o}}$ 1227, Centre for Economic Policy Research, London.

WILSON, Rob A. (1997). Review of the Economy and Employment. Coventry, Institute for Employment Research, University of Warwick. 
Reestruturação, Requalificação e Dispensas: Um Estudo da Dinâmica...

\section{APÊNDICE}

\section{Quadro A1}

Análise de Regressão da Mobilidade Líquida das Qualificações 1991-95

\begin{tabular}{|l|c|c|c|c|c|}
\hline \multicolumn{7}{|c|}{ Coeficientes* } \\
\hline \multirow{4}{*}{ (Constante) } & $\begin{array}{c}\text { Coeficientes não } \\
\text { padronizados }\end{array}$ & \multicolumn{3}{|c|}{$\begin{array}{c}\text { Coeficientes } \\
\text { padronizados }\end{array}$} \\
\cline { 2 - 7 } Homens & B & Erro padrão & beta & $\mathbf{t}$ & sig \\
\cline { 2 - 6 } Nunca economicamente inativos & 0,079 & 0,027 & & 2,934 & 0,003 \\
Continuamente empregados & 0,003 & 0,011 & 0,003 & 0,263 & 0,793 \\
Número de dispensas & 0,025 & 0,024 & $-0,024$ & $-1,040$ & 0,300 \\
Número de dispensas com desemprego & 0,030 & 0,027 & 0,031 & 1,108 & 0,300 \\
Número de fases de desemprego & $-0,049$ & 0,020 & $-0,042$ & $-2,500$ & 0,013 \\
Nunca desempregados & 0,004 & 0,010 & $-0,007$ & $-0,358$ & 0,721 \\
24-24 anos & $-0,025$ & 0,028 & $-0,021$ & $-0,890$ & 0,373 \\
$35-44$ anos & 0,005 & 0,017 & 0,005 & 0,293 & 0,769 \\
$45-54$ anos & $-0,011$ & 0,018 & $-0,009$ & $-0,612$ & 0,541 \\
55 anos e mais & $-0,035$ & 0,018 & $-0,030$ & $-1,940$ & 0,053 \\
\hline *Variável dependente: Mobilidade líquida das qualificações, $1991-95$. \\
\hline
\end{tabular}




\section{Quadro A2}

Análise de regressão da mobilidade líquida dos rendimentos, 1991-1995

\begin{tabular}{|l|c|c|c|c|c|}
\hline \multicolumn{5}{|c|}{ Coeficientes* } \\
\hline & $\begin{array}{c}\text { Coeficientes não } \\
\text { padronizados }\end{array}$ & \multicolumn{3}{|c|}{$\begin{array}{c}\text { Coeficientes } \\
\text { padronizados }\end{array}$} \\
\cline { 2 - 7 } & B & Erro padrão & beta & t & sig \\
\cline { 2 - 7 } (Constante) & 0,839 & 0,099 & & 8,441 & 0,000 \\
Homens & $-0,490$ & 0,040 & $-0,014$ & $-1,230$ & 0,217 \\
Nunca economicamente inativos & $-0,137$ & 0,088 & $-0,036$ & $-1,550$ & 0,121 \\
Continuamente empregados & 0,199 & 0,100 & 0,055 & 1,981 & 0,048 \\
Número de dispensas & $-0,231$ & 0,071 & $-0,055$ & $-3,250$ & 0,001 \\
Número de dispensas com desemprego & 0,107 & 0,108 & 0,018 & 0,994 & 0,320 \\
Número de fases de desemprego & $-0,059$ & 0,036 & $-0,031$ & $-1,650$ & 0,100 \\
Nunca desempregados & $-0,159$ & 0,101 & $-0,360$ & $-1,580$ & 0,114 \\
$24-24$ anos & $-0,415$ & 0,062 & $-0,103$ & $-6,666$ & 0,000 \\
35-44 anos & $-0,545$ & 0,065 & $-0,127$ & $-8,380$ & 0,000 \\
45-54 anos & $-0,690$ & 0,670 & $-0,157$ & $-10,300$ & 0,000 \\
55 anos e mais & $-0,950$ & 0,070 & $-0,191$ & $-13,600$ & 0,000 \\
\hline *Variável dependente: Mobilidade líquida dos rendimentos, $1991-95$. \\
\hline
\end{tabular}

Quadro A3

Análise de Regressão da Mobilidade Líquida dos Rendimentos e da Mudança nas Qualificações 1991-1995

\begin{tabular}{|l|c|c|c|c|c|}
\hline \multicolumn{7}{|c|}{ Coeficientes } \\
\hline \multirow{2}{*}{ (Constante) } & B & Erro padrão & beta & t & sig \\
\cline { 2 - 7 } Homens & 0,831 & 0,101 & & 8,233 & 0,000 \\
Nunca economicamente inativos & $-0,050$ & 0,040 & $-0,140$ & $-1,250$ & 0,210 \\
Continuamente empregados & $-0,130$ & 0,090 & $-0,033$ & $-1,450$ & 0,147 \\
Número de dispensas & 0,188 & 0,101 & 0,052 & 1,853 & 0,064 \\
Número de dispensas com desemprego & $-0,224$ & 0,072 & $-0,052$ & $-3,100$ & 0,002 \\
Número de fases de desemprego & $-0,059$ & 0,109 & 0,020 & 1,098 & 0,272 \\
Nunca desempregados & $-0,155$ & 0,037 & $-0,030$ & $-1,590$ & 0,112 \\
24-24 anos & $-0,430$ & 0,063 & $-0,035$ & $-1,520$ & 0,130 \\
35-44 anos & $-0,691$ & 0,066 & $-0,130$ & $-6,820$ & 0,000 \\
$45-54$ anos & $-0,950$ & 0,680 & $-0,157$ & $-10,200$ & 0,000 \\
55 anos e mais & $-0,381$ & 0,071 & $-0,190$ & $-13,400$ & 0,000 \\
Mobilidade líquida das qualificações & 0,381 & 0,040 & 0,103 & 9,517 & 0,000 \\
\hline *Variável dependente: Movimento líquido dos ganhos entre decis, 1991-95. \\
\hline
\end{tabular}




\section{Quadro A4}

Análise de Regressão da Mobilidade Líquida dos Rendimentos, Mudança das Qualificações e do Treinamento relativo ao Trabalho 1991-95

\begin{tabular}{|l|c|c|c|c|c|}
\hline \multicolumn{5}{|c|}{ Coeficientes* } \\
\hline & B & $\begin{array}{c}\text { Erro } \\
\text { padrão }\end{array}$ & beta & t & sig \\
\cline { 2 - 6 } (Constante) & 0,761 & 0,104 & & 7,323 & 0,000 \\
Homens & $-0,047$ & 0,040 & $-0,130$ & $-1,170$ & 0,240 \\
Nunca economicamente inativos & $-0,127$ & 0,090 & 0,032 & $-1,410$ & 0,158 \\
Continuamente empregados & 0,173 & 0,102 & 0,048 & 1,700 & 0,089 \\
Número de dispensas & $-0,208$ & 0,074 & $-0,048$ & $-2,800$ & 0,005 \\
Número de dispensas com desemprego & 0,123 & 0,109 & 0,021 & 1,131 & 0,258 \\
Número de fases de desemprego & $-0,062$ & 0,037 & $-0,032$ & $-1,660$ & 0,098 \\
Nunca desempregados & $-0,147$ & 0,103 & $-0,033$ & $-1,440$ & 0,151 \\
24-24 anos & $-0,439$ & 0,063 & $-0,108$ & $-6,960$ & 0,000 \\
35-44 anos & $-0,562$ & 0,066 & $-0,131$ & $-8,560$ & 0,000 \\
45-54 anos & $-0,693$ & 0,068 & $-0,157$ & $-10,300$ & 0,000 \\
55 anos e mais & $-0,963$ & 0,071 & $-0,185$ & $-13,000$ & 0,000 \\
Treinamento relacionado ao trabalho re- & 0,121 & 0,040 & 0,033 & 2,985 & 0,003 \\
cebido, 1991-95 & & & & & \\
Treinamento relacionado ao trabalho re- & $-0,193$ & 0,164 & $-0,014$ & $-1,180$ & 0,238 \\
cebido no emprego seguinte à dispensa & & & & & \\
Mobilidade líquida das qualificações & 0,379 & 0,040 & 0,102 & 9,456 & 0,000 \\
\hline *Variável dependente: Movimento líquido dos ganhos entre decis, 1991-95. \\
\hline
\end{tabular}


Quadro A5

Médias das Variáveis Usadas nas Regressões de Mobilidade das Qualificações e Mobilidade dos Rendimentos

\begin{tabular}{|l|c|c|}
\hline Variável & $\begin{array}{c}\text { Regressões de Mo- } \\
\text { bilidade das Quali- } \\
\text { ficações }\end{array}$ & $\begin{array}{c}\text { Regressões de Mo- } \\
\text { bilidade dos Rendi- } \\
\text { mentos }\end{array}$ \\
\hline Homens & 0.52 & 0.51 \\
Nunca economicamente inativos & 0.70 & 0.70 \\
Continuamente empregados & 0.59 & 0.59 \\
№ de dispensas & 0.14 & 0.14 \\
№ de dispensas com desemprego & 0.08 & 0.08 \\
№ de períodos de desemprego & 0.38 & 0.37 \\
Nunca desempregados & 0.79 & 0.80 \\
16-24 anos & 0.16 & 0.16 \\
25-34 anos & 0.26 & 0.26 \\
35-44 anos & 0.22 & 0.22 \\
45-54 anos & 0.20 & 0.21 \\
55 anos e mais & 0.15 & 0.15 \\
Receberam treinamento relacio- & 0.58 & 0.59 \\
nado ao trabalho & & 0.02 \\
Receberam treinamento relacio- & 0.02 & \\
nado ao trabalho no emprego se- & & \\
guinte à demissão por extinção & & \\
de cargo ou função & & \\
№ de observações & & \\
\hline
\end{tabular}

Notas: 1. Estas diferenças estão relacionadas a um período contínuo durante 1991-95 em que o informante fazia parte do painel.

2. As informações relativas ao treinamento somente se referem às pessoas empregadas em cada rodada da pesquisa. 


\begin{abstract}
Restructuring, Reskilling and Redundancy: A Study of the Dynamics of the UK Labour Market, 1991-95

This study reveals the longer term consequences of redundancy, shown to include discontinuous employment, deskilling and significant movement down the earnings distribution. Using evidence from the British Household Panel Survey, it is shown that craft and low-skilled occupations experienced the major share of redundancies in the period 1991-95. Workers made redundant are less likely to work in future years and are more likely to experience significant downward movements in their occupational position and earnings. Work-related training is received by a good proportion of ex-redundant workers who regained employment during the period studied, but no evidence was found to support the hypothesis that the experience of training may protect them from the negative consequences of redundancy.
\end{abstract}

Key words: restructuring; reskilling; redundancy; labour market

\title{
RÉSUMÉ
}

Restructuration, Requalification et Licenciement: Une Étude des

Dynamiques Animant le Marché du Travail Britannique, 1991-95

Dans cette étude, on révèle les conséquences à long terme du licenciement, concept incluant l'emploi discontinu, la déqualification et la réduction significative des salaires. Les données fournies par le British Household Panel Survey montrent que les emplois de l'artisanat ou à basse qualification sont les plus touchés par les vagues de licenciement pendant la période 1991-1995. Les personnes licenciées auraient plus de difficultés à trouver du travail dans les années qui suivent leur licenciement, et la plupart se verraient attribuer des emplois de qualité inférieure en termes de salaire. Des séances de training ont été généralement suivies par les personnes licenciées ayant retrouvé un emploi pendant la période étudiée, mais rien ne prouve que ces séances les protègent des effets négatifs du licenciement.

Mots-clé: restructuration; requalification; licenciement; marché du travail 